$+\infty$
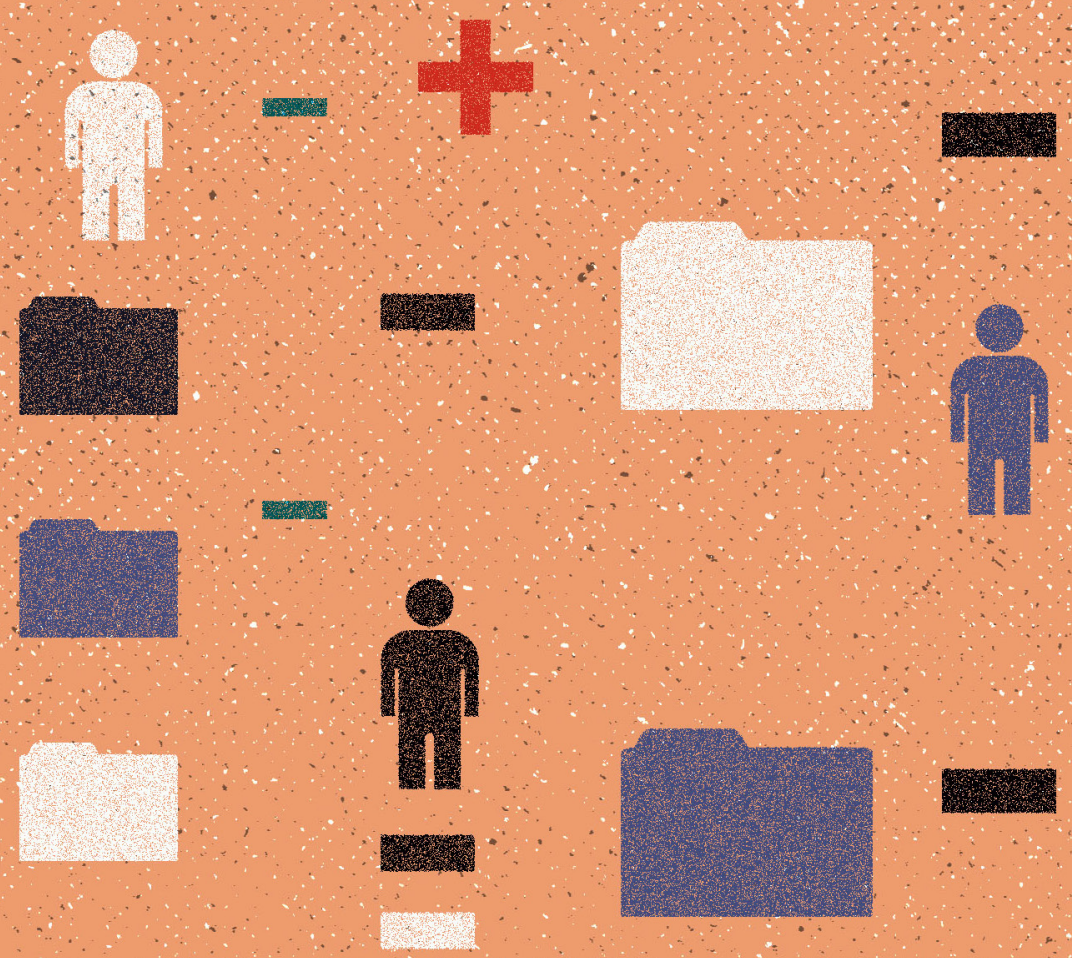

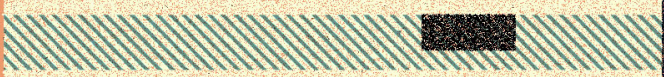
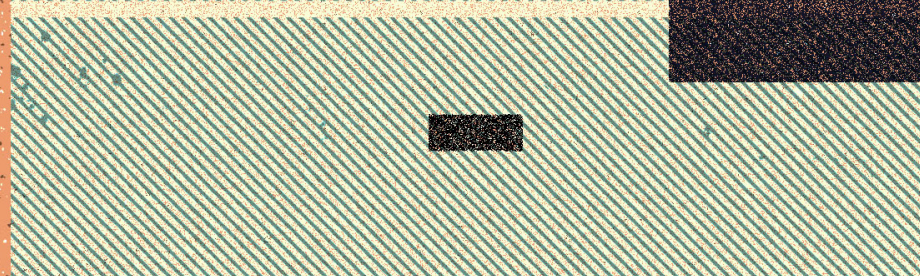

IMIIIIII

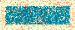

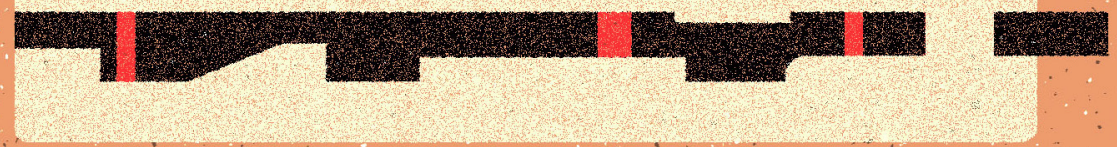




\title{
Políticas Públicas e Desenvolvimento Regional: a relação entre os repasses públicos e o desenvolvimento brasileiro
}

\author{
Public Policies and Regional Development: \\ The relationship between public transfers and \\ Brazilian development
}

\author{
Simão Ternoski* | Marcio Gazolla** \\ Marcos Junior Marini*** | Miguel Angelo Perondi****
}

Resumo

Momentos de maior fragilidade social, como o atual cenário de pandemia do Covid19 evidenciam a indispensável e necessária atuação do Estado, garantindo renda mínima e defesa dos mais vulneráveis, apesar disso, o cenário brasileiro dos últimos quatro anos intensificou o embate entre as forças sociais, algumas apregoando o corolário do Estado mínimo e, outras, reforçando a importância das políticas públicas na equalização das desigualdades. Este processo social bipolar, instiga ao objetivo de monitorar as relações de efeito no repasse de políticas públicas sobre o Produto Interno Bruto PIB e o Índice Firjan de Desenvolvimento Municipal - IFDM, analisados no período de 2005-2016, a partir dos dados em painel de todos os municípios brasileiros. As políticas avaliadas explicam o PIB e o IFDM no cenário macro, mas, regionalmente, o Fundo de Participação dos Municípios e o Benefício de Prestação Continuada geram maiores efeitos na equalização da renda e bem-estar entre as regiões.

Palavras-chave: Política Distributiva; Política Redistributiva; Riqueza; Qualidade de Vida.

\begin{abstract}
The COVID19 context reveals the greater social fragility and the indispensable action of the State to support the minimal income and defense of the most vulnerable people. Despite this, the Brazilian scenario of the last four years has intensified the clash between the corollary of the minimum state and the importance of equalizing public policies. This bipolar social process instigates the objective of monitoring the effect relationships in the transfer of public policies on the Gross Domestic Product GDP and the Firjan Municipal Development Index - IFDM. The analyse, based on the panel data from 2005 to 2016 of all Brazilian municipalities reveals that the evaluated policies explain the GDP and the IFDM in the macro scenario, and, in the regionally view, occurs two policies that generated the greater effect on the equalization of income and well-being between regions: (a) Municipality Participation Fund and (b) Continued Installment Benefit stand out.
\end{abstract}

Keywords: Distributive Policy; Redistributive Policy; Wealth; Quality of life.

\footnotetext{
* Doutorando e Mestre em Desenvolvimento Regional (UTFPR) e Professor do Departamento de Ciências Econômicas da Universidade Estadual do Centro-Oeste - UNICENTRO. https://orcid.org/0000-0003-1227-7966. E-mail: sternoski@unicentro.br

** Doutor em Desenvolvimento Rural (UFRGS) e Docente do Programa de Pós-Graduação em Desenvolvimento Regional (PPGDR) da Universidade Tecnológica Federal do Paraná (UTFPR) - Campus Pato Branco.

https://orcid.org/0000-0002-4807-6683.E-mail: marciogazolla1@gmail.com

*** Doutor em Tecnologia (UTFPR) e Docente do Programa de Pós-Graduação em Desenvolvimento Regional (PPGDR) da Universidade Tecnológica Federal do Paraná (UTFPR) - Campus Pato Branco.

https://orcid.org/0000-0003-2539-0335. E-mail: marini@utfpr.edu.br
}

**** Doutor em Desenvolvimento Rural (UFRGS) e Docente do Programa de Pós-Graduação em Desenvolvimento Regional (PPGDR) da Universidade Tecnológica Federal do Paraná (UTFPR) - Campus Pato Branco. https://orcid.org/0000-0003-4382-4571.E-mail: miguelangeloperondi@gmail.com

Recebido em 2 de maio de 2020. Aceito em 30 de julho de 2020. - http://dx.doi.org/10.51861/ded.dmv.2.009 


\section{INTRODUÇÃO}

O ambiente brasileiro das políticas públicas, para Lourenço (2005), passou por profundas mudanças na década de 1990, via esgotamento do modelo de desenvolvimento da década 1980 e a busca da estabilização da economia com políticas neoliberais, que acabaram por acirrar ainda mais a pobreza e as desigualdades. Embora nas décadas seguintes muitos programas e políticas públicas se consolidaram com viés social, de combate à desigualdade e a pobreza, cumprindo o que prevê a Constituição Federal de 1988 (CF), recentemente se observa um retrocesso destas políticas, intensificado a partir de 2016, com cortes e ajustes justificados na busca por retomar o crescimento econômico, um discurso que até o momento deste texto não se comprovou na forma de uma retomada da economia.

Por isso, o foco desse trabalho analisa os repasses públicos da série histórica dos anos de 2005-2016, pois este período coincide com o que a literatura tem chamado de social desenvolvimentismo, em que ocorreu um acelerado nascimento e redesenho de muitas políticas públicas (CASTRO, 2012). Procedendo desta forma, e analisando um período histórico com muitos recursos públicos, é mais fácil modelos econômicos captarem as influências dos repasses das políticas públicas sobre indicadores de desenvolvimento e de riqueza do país, inclusive, em modelos regionalizados.

Após este período, escolhido para a análise deste estudo, percebe-se a intensificação do contingenciamento e ajustes das políticas públicas outrora incentivadas. Por exemplo, o Programa Bolsa Família (PBF), cujos dados obtidos do VIS DATA (2019a) e corrigidos pelo Índice Nacional de Preços ao Consumidor Amplo (IPCA) para dezembro de 2018, indicam a existência de variações negativas nos repasses entre 2015 e 2018, com a exceção de uma pequena variação positiva de $0,14 \%$ em 2017. Já segundo a Agência Senado (2019) a Previdência Social também passou por ajustes, com a Proposta de Emenda Constitucional (PEC 6/2019), estimando uma economia em 10 anos de 800 bilhôes.

O cenário de Estado mínimo brasileiro, e de retrocessos de muitas políticas públicas, intensificado principalmente a partir de 2016, instiga ao problema de pesquisa, no sentido de questionar, qual o impacto dos recursos injetados pelas políticas públicas distributivas e redistributivas em indicadores de riqueza e de desenvolvimento no Brasil e suas regióes? Como indicador de riqueza, usa-se o Produto Interno Bruto (PIB), e de desenvolvimento o Índice Firjan de DesenvolvimentoMunicipal (IFDM). Pressupõe-se como hipóteses: Hipótese nula $\left(\mathrm{H}_{0}\right)$ : Ausência de impacto probabilístico positivo ou negativo das políticas públicas sobre o PIB e o IFDM; Hipótese alternativa $\left(\mathrm{H}_{1}\right)$ : Presença de efeito probabilístico positivo ou negativo das políticas 
públicas distributivas e redistributivas no PIB e no IFDM dos municípios brasileiros.

O trabalho possui o objetivo geral de monitorar as relaçóes de efeito entre o repasse de uma política distributiva e de cinco políticas redistributivas sobre o PIB e o IFDM, no período de 2005 a 2016. Enquanto objetivos mais específicos, o artigo abrange: a) levantar o volume repassado com o Benefício de Prestação Continuada (BPC), Programa Bolsa Família (PBF), Previdência Social, Fundo de Participação dos Municípios (FPM), Fundo de Manutenção e Desenvolvimento da Educação Básica (FUNDEB) mais Fundo de Manutenção e Desenvolvimento do Ensino Fundamental e de Valorização do Magistério (FUNDEF) e Imposto Territorial Rural (ITR) dos municípios brasileiros, no período de 2005 a 2016; b) descrever as variáveis por meio da estatística descritiva; e c) aplicar modelo econométrico de efeitos fixos para dados em painel estimando a relação probabilística das políticas avaliadas sobre o IFDM e sobre o PIB, também, em modelo espacial para as macrorregióes do país.

A importância do estudo se justifica na necessidade de avaliar as respostas dos recursos repassados pelas políticas públicas sobre os processos de desenvolvimento/qualidade de vida (IFDM) e de riqueza/crescimento (PIB). Se torna relevante ao entender o papel do Estado, via políticas públicas para agir na redução da desigualdade, miséria e na promoção do bem-estar da população, já que está é uma das principais estratégias de desenvolvimento que as nações podem contar (THOMAS, 2000).

A pesquisa está estruturada, além desta introdução, em outras 4 seções, inicia com a discussão teórica que relaciona as políticas públicas ao desenvolvimento e crescimento, na sequência, apresenta as ferramentas metodológicas. Segue-se com uma seção de resultados, que em um primeiro momento descreve o comportamento do PIB, do IFDM e das políticas analisadas, e na sequência apresenta os resultados do modelo inferencial, por fim, estão as discussões finais.

\section{POLİTICAS DISTRIBUTIVAS E REDISTRIBUTIVAS E O DESENVOLVIMENTO ECONÔMICO REGIONAL}

Ao avaliar o papel do Estado e das políticas públicas é importante entender que a própria política é milenar e remete a civilização Grega, tendo tanto o seu papel como o papel do Estado reafirmado após as guerras mundiais e a depressão econômica de 1929, uma vez que a ideia de progresso do século XVIII, pautada no crescimento linear e no livre mercado, já não era mais suficiente (SOUZA, 2006; FREY, 2000). Surge então, a busca pelo desen- 
volvimento, que não se limita a percepção puramente econômica, envolve também as oportunidades, melhorias da qualidade de vida e liberdades desfrutadas, visto que, unicamente a riqueza e crescimento levariam a uma maior desigualdade (SEN, 2000; FURTADO, 1980; TAVARES, 2019).

O desenvolvimento ainda deve ser pautado em bases sustentáveis, contemplando, de acordo com Sachs (1994) aspectos para além do econômico, mas que envolvam o social, o ecológico, as culturas e os espaços. E, além do mais, deve atender as necessidades humanas de maneira igualitária, garantindo "os recursos que sustentarão as geraçôes presentes e futuras" (NACIONES UNIDAS, 1987, p. 16).

Expandir esta percepção para além do econômico permite valorizar os aspectos sociais e suas carências, respeitando os diferentes modos de vida, um desenvolvimento moldado em uma construção social que valoriza as especificidades do local como forma de resolver os problemas da fome, miséria, crises, dentre outros. O risco de se reproduzir modelos externos é criar desastres estruturais e sociais, daí a importância do olhar ao local (FURTADO, 1980; GUDYNAS, 2011; SCHNEIDER, ESCHER, 2011; THEIS, GALVÃO, 2012).

Amaral Filho (2001, p. 262) reafirma o papel do local, ao considerar que o desenvolvimento endógeno é "um processo de crescimento econômico que implica uma contínua ampliação da capacidade de agregação de valor sobre a produção", já para Marini et al (2012) seria o resultado do processo de articulação dos atores locais. O local é um ambiente de intensa interatividade, repleto de ativos relacionais e de capital social, que permite aos agentes a eficiência produtiva e uma demanda diferenciada, ressaltado o papel das políticas e do Estado como forma de prover o desenvolvimento regional (BECATTINI, 1991; SCHIMITZ \& NADVI, 1999; CAVALCANTE, 2015).

O Estado, via políticas públicas, pode destacar as potencialidades locais, minimizar os problemas e propor meios ao desenvolvimento, açóes que rompem com o individualismo e criam um ambiente que conduz ao maior bem-estar social. As linhas de atuação fazem frente às necessidades públicas, desde aspectos sociais, como saúde, educação, emprego, habitação, etc. até questóes gerais como as políticas fiscal, monetária e cambial, ou áreas de tecnologia e agrárias (HEIDEMANN, 2009; SOUZA, 2006; RAEDER, 2014; GELINSKI \& SEIBEL, 2008).

As políticas públicas são promotoras do desenvolvimento, espalhando "os benefícios do crescimento, alcançando um número maior de pessoas", dão ao Estado a possibilidade de equalizar a capacidade de desenvolvimento das regiões (FEIJÓ, 2007, p. 44). O enfoque regional ganhou força, no Brasil, na década de 1950, buscando corrigir os desequilíbrios e a desigualdade entre 
as regiões, promovendo o bem-estar e protegendo os grupos com maior vulnerabilidade social, visto que as políticas macroeconômicas nem sempre permitiam atingir uma maior igualdade (DINIZ \& CROCCO, 2006; IPEA, 2018; ROTTA \& REIS 2007). Esta atuação do Estado, na percepção de Secchi (2013), Souza (2006) e Frey (2000) a partir de Lowi (1972), se consolida nas políticas distributivas, redistributivas, regulatórias e constitutivas.

As políticas distributivas geram benefícios mais pontuais e possuem menor grau de conflito, os benefícios desta política e da distribuição do bem público permitem atingir inclusive os opositores. O risco deste tipo de política é favorecer o clientelismo, sem uma consideração a respeito dos custos, já que a impressão é que são distribuídas apenas vantagens (SECCHI, 2013; SOUZA, 2006; FREY, 2000; TUDE, FERRO \& SANTANA, 2015).

Já na via das políticas redistributivas os conflitos estão presentes, dado o claro deslocamento do recurso em favorecimento de uma classe, sendo retirado de uma parcela ou grupo em benefício de outro (SECCHI, 2013; SOUZA, 2006; FREY, 2000). Para Melazzo (2010) e Tude, Ferro e Santana (2015) estes conflitos atingem grandes grupos sociais, com perdas a alguns e ganhos a outros.

Ainda nesta esfera de classificação da política, as regulatórias são as menos perceptíveis, e tratam das normas da política, envolvendo a administração pública, regulamentos, decretos, normas e a própria burocracia (MELAZZO, 2010). Frey (2000) considera que estas políticas não deixam claro seus custos, uma vez que estes dependem do desenrolar da política no momento da implantação.

Por fim, as constitutivas determinam a estrutura dos próprios conflitos e da política em si, estabelecendo as regras do sistema de governo, do sistema eleitoral e das instituiçóes, isso gera impactos nas condiçóes para a proposição das políticas distributivas, regulatórias e redistributivas (SECCHI, 2013; SOUZA, 2006; FREY, 2000). Melazzo (2010) complementa que as constitutivas criam as normas para que as demais políticas possam ser implantadas.

Voltando-se para as políticas objeto deste estudo (distributivas e redistributivas) a literatura relaciona seus efeitos positivos, sobre as oportunidades, renda, desenvolvimento e crescimento. Permitem reduzir a desigualdade e a pobreza ao gerar as condições aos grupos menos favorecidos no enfrentamento dos problemas, mas, dependem da existência de crescimento econômico para o seu financiamento (BARRETO, 2005; LANZARA, 2016).

Draibe (2003) reforça que as políticas redistributivas, a exemplo da previdência e da assistência social, geram o desenvolvimento e o combate à pobreza. Mas, apesar de equalizarem a renda, corrigirem ineficiências dos mercados, e criarem oportunidades as populações carentes, Prebisch (2000) 
e Kerstenetzky (2009), consideram que estas políticas estão limitadas ao menor volume de recursos disponíveis para redistribuir, se comparadas aos recursos das políticas universais de renda.

Castro (2013) afirma que as políticas redistributivas reduzem a desigualdade, criando um efeito multiplicador sobre a renda, o que aquece não só o consumo, mas também gera emprego, produção e propriamente renda, e se tornam estratégias de desenvolvimento. Abrucio (2005) e Duarte (2000) atribuem ao efeito redistributivo a função equalizadora, ao gerar bem-estar (desenvolvimento) e riqueza (crescimento) nas classes mais pobres.

Estas políticas, de acordo com Magalhães (2006, p. 193) fomentam ainda o "mercado interno viabilizando a retomada do crescimento para dentro". Para Neri et al (2013), Mostafa et al (2010), e Massuda et al (2019) é evidente o efeito multiplicador das políticas distributivas e redistributivas sobre o crescimento e o desenvolvimento. Neste ponto, a presente pesquisa se aproxima desta literatura, ao identificar o efeito multiplicador gerado pelas políticas avaliadas, distanciando-se das abordagens teóricas expostas pela sua especificidade de análise que se volta a investigar somente uma política distributiva e cinco redistributivas.

Mesmo que seja visível uma relação positiva, ainda persiste o desafio que vai desde a proposição até a implantação da política, fato este, ligado a heterogeneidade dos territórios, como suas questôes culturais, políticas, econômicas, entre outras (DINIZ \& CROCCO, 2006). Além disso, é fundamental avaliar constantemente se os objetivos das políticas estão sendo atingidos, mesmo diante da limitação dos diversos modelos em capturar todas as especificidades (BAPTISTA \& REZENDE, 2015; DYE, 2009; FREY, 2000; RAEDER, 2014).

Dye (2009) aponta a existência de inúmeros modelos de avaliação das políticas públicas, como: institucional; de grupo; de elite; racional; incremental; da teoria de jogos; da opção pública; e sistêmico. Estas formas diversas de se avaliar não são competitivas, em que um modelo sobressaia ao outro.

Neste sentido, o estudo optou pelo modelo estatístico para avaliação, com resultados econométricos do efeito das políticas sobre o desenvolvimento e crescimento, mas entende, que a abordagem poderia ser realizada por qualquer outro tipo de modelo, a exemplo dos propostos por Dye (2009), onde o foco da avaliação seria alterado de acordo com o modelo escolhido. Neste caso, valorizaria, por exemplo, a participação (efeito) das instituições, dos grupos com seus interesses, etc., enfim, valorizando determinada área de análise de acordo com o foco do modelo escolhido.

As políticas públicas, objeto da análise, são políticas que se figuram no campo distributivo e redistributivo. Em uma frente o estudo considera as 
políticas de assistência social, da qual, o Benefício de Prestação Continuada (BPC) (política distributiva) que garante um salário aos idosos e pessoas com deficiência em famílias com renda por integrante de até $1 / 4$ de salário mínimo. Outra política de assistência, mas no campo redistributivo, é o Programa Bolsa Família (PBF), que compreende o repasse de renda para famílias com rendimento de até $\mathrm{R} \$ 178,00$ mensais, visando a superação da fome e da pobreza. Ambas políticas integram as linhas de combate à pobreza (VIS DATA, 2019a).

Uma segunda via de análise é sobre a Seguridade Social, que inclusive é prevista no art. 6o da Constituição Federal. Os dados da Previdência Social (política redistributiva) estão apresentados entre arrecadação e pagamentos. A arrecadação engloba as guias de recolhimento, contribuiçóes de empresas e outras entidades; já os pagamentos envolvem benefícios concedidos, encargos e refletem o repasse líquido (SECRETARIA DE PREVIDÊNCIA, 2019).

Em uma terceira via estão as Transferências Constitucionais (na esfera redistributiva), voltadas ao equilíbrio socioeconômico através do rateio aos Estados e municípios de parte da arrecadação da União. Optou-se por avaliar o Fundo de Participação dos Municípios (FPM), previsto no art. 159 da Constituição Federal (CF); o Fundo de Manutenção e Desenvolvimento da Educação Básica e de Valorização dos Profissionais da Educação (FUNDEB); e o Imposto sobre a Propriedade Territorial Rural (ITR) que via art. $158 \mathrm{da}$ CF estabelece o retorno de 50\% deste imposto aos municípios (TESOURO NACIONAL, 2019).

O FUNDEB substituiu o Fundo de Manutenção e Desenvolvimento do Ensino Fundamental e de Valorização do Magistério (FUNDEF), extinto em 2006. Atende alunos desde a creche até o ensino médio com recursos que são destinados via o número de alunos no censo escolar (MEC, 2019). Os dados do FUNDEF e FUNDEB foram unidos tendo em vista a proporcionar uma continuidade da série histórica.

Pela perspectiva do crescimento e do desenvolvimento, a pesquisa engloba o índice Firjan de Desenvolvimento Municipal (IFDM) e o Produto Interno Bruto (PIB). Firjan (2018) aponta que o IFDM é calculado em três dimensóes: a) Emprego e Renda: englobando o índice de Gini, mercado formal de trabalho e sua massa salarial, geração de emprego formal e a geração de renda; b) Educação: envolvendo as variáveis do Índice de Desenvolvimento da Educação Básica (IDEB), horas aulas diárias e professores com ensino superior no ensino fundamental, atendimento a educação infantil, além da distorção de série no ensino fundamental e o abandono; c) Saúde: contemplando os óbitos mal definidos e óbitos infantis evitáveis, a proporção de atendimentos do pré-natal (adequadas) e as internações na atenção básica. 
O cálculo é dado em escala de 0 (zero) a 1 (um), sendo que mais próximo de 1 , maior é o desenvolvimento. Mas, convencionou-se uma escala de quatro conceitos, onde: IFDM entre 0,0 e 0,4 é atribuído ao baixo desenvolvimento; de 0,4 a 0,6 desenvolvimento regular; de 0,6 a 0,8 desenvolvimento moderado; e de 0,8 a 1,0 alto estágio de desenvolvimento (FIRJAN, 2018).

Em termos do PIB, Blanchard (2011, p. 18) considera como o "valor dos bens e serviços finais produzidos em uma economia em um dado período de tempo". Para o IBGE (2015) o PIB contempla o valor adicionado bruto dos setores industrial, agropecuário, administração pública, serviços e impostos, no período de um ano, geralmente civil (janeiro a dezembro).

\section{PROCEDIMENTOS METODOLÓGICOS}

Com vistas a atingir o propósito da pesquisa, assume-se a característica descritiva, de natureza quantitativa e o uso de fontes secundárias. A análise dos dados é feita com a estatística descritiva, via tabelas, gráficos, média simples e geométrica e coeficiente de variação, além do uso de modelo econométrico de efeitos fixos para dados em painel. O período de análise, 2005 a 2016, foi escolhido diante da disponibilidade dos dados, sendo que, 2005, no momento da coleta de dados, era o primeiro ano com dados da série do Índice Firjan de Desenvolvimento Municipal (IFDM) e, 2016, como o último ano de disponibilidade do Produto Interno Bruto - PIB, além do que, após 2016 ocorreu o acelerado desmonte de algumas das políticas públicas.

As variáveis foram tratadas por meio do modelo econométrico próprio descrito na equação 01 , cujo teste da hipótese considerou o nível mínimo de $95 \%$ de confiabilidade estatística, portanto, todo valor de probabilidade (p-valor) menor ou igual a 5\% leva a rejeição da hipótese nula e ao aceite da hipótese alternativa (presença de efeito probabilístico). Gujarati (2006) considera que dados de painel combinam séries temporal com dados de corte, permitindo acompanhar entidades ao longo do tempo, uma característica presente nos dados que acompanharam os 5.570 municípios em 12 anos, produzindo 66.840 observaçóes. Destaca-se ainda, que todas variáveis com valores monetários foram inflacionadas pelo índice de preços ao consumidor para dezembro de 2016 (IBGE, 2019c).

$I F D M_{i t}$ e $\ln P I B_{D i t}=\alpha_{i t}+\beta_{1} \ln V R B P C_{D i t}+\beta_{2} \ln N P B P C_{i t}+\beta_{3} \ln V R B O L_{D i t}+$ $\beta_{4} \ln F B B O L_{i t}+\beta_{5} \ln P R E V A R R_{D i t}+\beta_{6} \ln P R E V P A G_{D i t}+\beta_{7} \ln F P M_{D i t}+$ $\beta_{8} \ln F U N D e f e b_{D i t}+\beta_{9} \operatorname{lnITR} R_{i t}+\beta_{10} \ln P O P_{i t}+\mu_{i t}$ 
Sendo:

$I F D M / \ln P I B_{D}=$ Variáveis dependentes ou explicadas, as quais o Índice Firjan de desenvolvimento municipal; e o logaritmo neperiano do Produto Interno Bruto;

$\alpha=$ Inclinação e intercepto entre os indivíduos (municípios) e ao longo do tempo;

$\beta_{1} ; \beta_{2} \ldots \beta_{n}=$ Parâmetros de peso entre a variável independente sobre a explicada;

$\operatorname{lnVRBPC_{D}}=$ Valor em logaritmo neperiano dos repasses com o Benefício de Prestação Continuada - BPC aos idosos e deficientes físicos dos municípios brasileiros;

lnNPBPC = Logaritmo neperiano da população beneficiária do BPC;

$\operatorname{lnVRBOL_{D}}=$ Logaritmo neperiano do valor repassado com Bolsa Família aos municípios brasileiros;

$\operatorname{lnFBBOL=}$ número de famílias beneficiárias do Bolsa Família, em logaritmo neperiano;

$\ln P R E V A R R_{D}=$ Logaritmo neperiano das arrecadaçóes da previdência social junto aos municípios;

InPREVPAG $=$ Logaritmo neperiano dos repasses com benefícios sociais da previdência social aos beneficiários dos municípios brasileiros;

$\ln F P M_{D}=$ Valores repassados em logaritmo neperiano via fundo de participação dos municípios;

lnFUNDefe $b_{D}=$ Repasses em logaritmo neperiano dos valores com FUNDEF (até 2006) mais FUNDEB (após 2006);

$\ln I T R=$ Logaritmo neperiano do imposto territorial rural dos municípios;

$\ln P O P=$ Número estimado em 1 o de julho do respectivo ano, em logaritmo neperiano, dos habitantes de cada município brasileiro para o período de 2005 a 2016;

$i=$ representa a $i$-ésima unidade de corte transversal (5.570 municípios);

$t=\mathrm{o} t$-ésimo período de tempo, que compreende os 12 anos da série;

$\mu_{i, t}=$ Termo de erro (resíduo).

A restrição do modelo proposto decorre da não normalidade na distribuição dos resíduos, fato resultante da heterogeneidade de contextos e volumes de recursos financeiros de cada município. Foram feitos testes convertendo as variáveis em índices e em logaritmo neperiano $(l n)$; optou-se pelo uso do ln devido ao menor coeficiente de variação $(\mathrm{CV})$ relacionado a cada uma das 
variáveis ${ }^{1}$. Mesmo com o CV indicando homogeneidade de boa parte das variáveis, o teste de wald rejeitou $H_{0}$ (modelo com erro padrão robusto), não permitindo afirmar a homocedasticidade ${ }^{2}$. Os resultados, sobretudo das variáveis com maior $\mathrm{CV}$, demandam análise cautelosa.

Dentre as variáveis explicadas o Índice Firjan de Desenvolvimento Municipal (IFDM) foi escolhido, mesmo não abarcando todas as dimensôes da qualidade de vida, devido sua série ser anual. Já o Produto Interno Bruto (PIB) por ser um indicador consagrado em termos da riqueza e crescimento. A série, coletada em IBGE (2019a) do PIB, identificou regionalidades como: municípios urbanos e rurais; cidades-região de São Paulo; Amazônia legal; e semiárido.

Entre as variáveis explicativas está uma política distributiva (Benefício de Prestação Continuada) e cinco políticas redistributivas (Bolsa Família, Previdência Social, Fundo de Participação dos Municípios, FUNDEB mais FUNDEF e Imposto Territorial Rural). Além da estimativa populacional do município em 1o de julho do respectivo ano (IBGE, 2019b).

Por fim, modelos em painel, segundo Wooldridge (2016), geram três resultados possíveis (Pooled; Efeito Fixo; ou Efeito Aleatório), e sua escolha depende dos testes de Chow, Breuch-Pagan e Hausman ${ }^{3}$. Os testes indicaram para o modelo de Efeito Fixo em todos os cenários. Inicialmente foram aplicados dois modelos principais (cenário macro), com dados de todos os municípios brasileiros, um primeiro com o IFDM como dependente e um segundo tendo o $\ln P I B$ como explicado.

$\mathrm{Na}$ sequência a análise foi regionalizada com 20 (vinte) submodelos (dez para o IFDM, e dez para o $\ln P I B$ ) com as mesmas variáveis, para os seguintes cenários: as cinco regióes brasileiras: Norte (com 450 municípios); Nordeste (1.794 casos); Sul (1.191 casos); Sudeste (1.668 casos); e Centro-Oeste (467 casos), e para a classificação de IBGE (2019a), sendo: municípios da Amazônia Legal (772 municípios); do Semiárido (1.262 casos); 140 municípios das cidades-região de São Paulo; municípios com mais de 50\% da população rural (1.624 municípios); e, por fim, para os 3.946 municípios com população urbana predominante.

\section{EFEITOS DOS RECURSOS INJETADOS PELAS POLİTICAS PÚBLICAS NAS REGIÕES E NA ECONOMIA}

A análise é feita em dois cenários, inicialmente a estatística descritiva apresenta o comportamento das variáveis no tempo e, na sequência, o modelo inferencial testa o efeito probabilístico das políticas sobre as dimen- 
sões da qualidade de vida (Índice Firjan de Desenvolvimento Municipal) e da riqueza (Produto Interno Bruto).

\section{Estatística descritiva do comportamento das variáveis no tempo}

O estudo contempla o Produto Interno Bruto (PIB) como dimensão de riqueza, e o Índice Firjan de Desenvolvimento Municipal (IFDM) como de qualidade de vida, mesmo entendendo a existência de outras métricas. Para o PIB os municípios estão separados, na Figura 01, em dois grupos: a) Mapa 01, os casos com PIB inferior à média nacional para o ano de 2016; e, b) Mapa 02, os municípios com o PIB superior à média.

É evidente o maior número de casos com PIB inferior à média, uma realidade reafirmada no comparativo entre a média e a mediana dos valores do PIB. O PIB médio para 2016 foi de 1,125 bilhôes, enquanto a mediana indica que 50\% dos municípios possuem PIB abaixo de $\mathrm{R} \$ 168,3$ milhôes. Aliado a isso, dos 5.570 municípios, 4.903 apresentaram PIB inferior à média, estes $88,03 \%$ concentram $17,78 \%$ da riqueza e os outros $11,97 \%$ ( 667 casos) detém $82,22 \%$ do PIB total, um fato que reflete a grande desigualdade econômica entre os municípios brasileiros.

Figura 01 - Municípios brasileiros com PIB superior e inferior à média para o ano de 2016
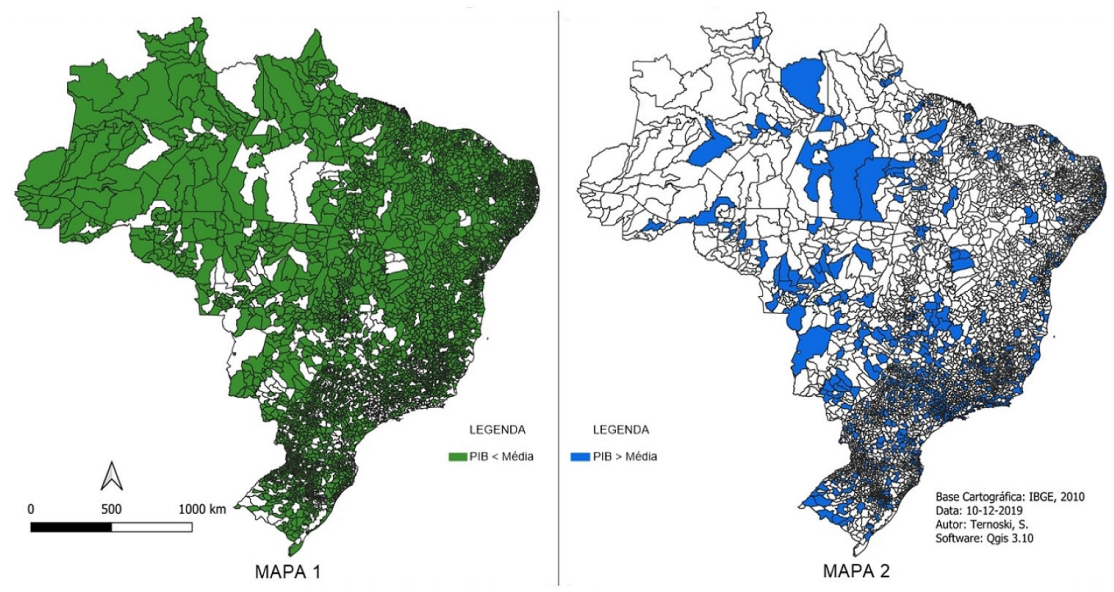

Fonte: Elaborado pelos autores a partir de IBGE (2019a)

Dos 667 municípios com produto superior ao PIB médio do país, 45,7\% e 24,3\% dos casos (467 municípios) estão respectivamente nas Regiões Sudeste e Sul, concentrando $60,6 \%$ da riqueza nacional ( $47,8 \%$ Sudeste e $12,8 \%$ Sul). 
A concentração é mais evidente quando 3 municípios (São Paulo, Rio de Janeiro e Brasília) detêm 19,98\% da riqueza do país. Só a cidade de São Paulo gera 687,03 bilhóes de PIB (o maior), quando por outro lado, o município de Miguel Leão, no Estado do Piauí, apresenta a menor riqueza (11,674 milhões).

Em uma análise regional nota-se que municípios do Norte, Nordeste e do Sul tem PIB um pouco melhor distribuído, onde 6,25\%, 6,21\% e 6,04\% respectivamente da riqueza total gerada nestas regióes fica entre os $50 \%$ dos municípios mais pobres, já no Sudeste e Centro-Oeste os 50\% mais pobres ficam com $2,24 \%$ e $4,05 \%$ do PIB total. No comparativo entre as regióes, 4,399 trilhões são gerados no Sul e Sudeste (53,2\% e 17\% da riqueza total), os outros 1,868 trilhões são produzidos entre o Nordeste (14,3\%),CentroOeste $(10,1 \%)$ e Norte $(5,4 \%)$.

Uma riqueza que além de concentrada em regiões, também se concentra em setores. O PIB do país em 2016 foi de 6,267 trilhôes, dos quais, a maior parcela vem do setor de serviços que gera 3,015 trilhóes aproximadamente ( $48 \%$ da riqueza), em seguida a indústria (18\%) com 1,15 trilhóes, e na sequência a administração pública, com 945 milhóes(15\%). Complementa o PIB os impostos com 849 milhóes (14\%) e o setor agropecuário com 306,6 milhões ( $5 \%$ da riqueza total).

Para o período analisado (2005-2016) a riqueza nacional apresentou crescimento geométrico médio de 3,96\%. A Figura 02 evidencia dois momentos deste período: um primeiro de crescimento (2005-2014) e, um segundo, de

Figura 02 - Evolução do PIB real por setores econômicos, período 2005/2016

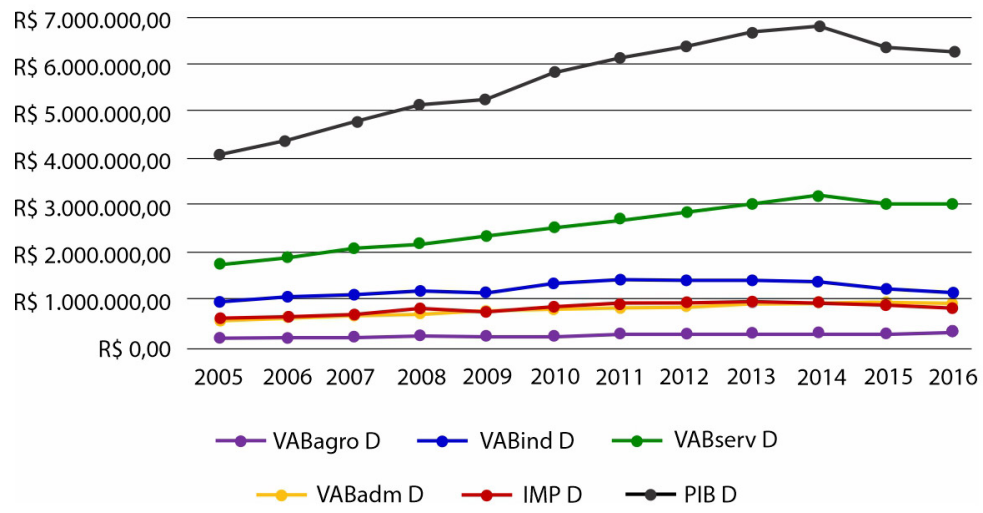

Fonte: Elaborado pelos autores a partir de IBGE (2019a)

Nota:Valores em escala 1 para 1.000.000,00, inflacionados pelo IPCA para 0 ano base 2016. 
variações negativas (2014-2016). Entre 2005-2014 o crescimento acumulado foi $66,27 \%$, mas, diante das variaçóes negativas de $6,25 \%$ entre $2014 / 2015$, e $1,66 \%$ de 2015/2016, fechou em 53,29\% o acumulado do período de 2005 a 2016.

O setor de serviços, o mais importante na composição do PIB, cresceu a uma taxa geométrica média de $5,14 \%$ no período, acumulando uma variação de $73,64 \%$, na sequência a administração pública cresceu $4,94 \%$ anual (70,01\% de variação no período), seguida do setor agropecuário com crescimento médio de $4,44 \%$ e acumulado de $61,26 \%$. Já as menores taxas de crescimento geométrico anual médio estão nos impostos 2,94\% (acumulando $37,6 \%)$ e na indústria ( $1,39 \%$ de crescimento médio anual), cuja variação entre 2005 e 2016 foi de $16,4 \%$.

Quando a dimensão da qualidade de vida expressa no Índice Firjan de Desenvolvimento Municipal (IFDM), a Figura 03, os apresenta em 4 grupos, estes: a) IFDM de 0,0 a 0,4 - baixo desenvolvimento, e casos inexistentes (amarelo); b) IFDM de 0,4 a 0,6 - desenvolvimento regular (vermelho); c) faixa de 0,6 a 0,8 (azul), com desenvolvimento moderado; d) em verde, IFDM entre 0,8 e 1,0 alto estágio de desenvolvimento.

$\mathrm{O}$ alto estágio de desenvolvimento ocorre em 7,74\% dos municípios, com maior frequência no Sul e Sudeste (em verde), já o desenvolvimento regular (vermelho) é realidade para 23,12\% dos casos, e mais perceptível no Norte e Nordeste. A maioria dos municípios $(67,16 \%)$ se encontram na condição moderada (azul) e a menor frequência de casos $(1,97 \%)$ incorrem em baixo desenvolvimento (amarelo), dos quais para 1,78\% o indicador não foi calculado (99 municípios). Nos extremos estão o município de Ipixuma/AM com índice de 0,321 (mais baixo) e Louveira/SP com índice de 0,901 (mais alto).

Regionalmente o Sul possui 15,03\% de seus municípios com alto desenvolvimento, seguida do Sudeste $(13,07 \%)$ e do Centro-Oeste $(6,21 \%)$, já o Norte e o Nordeste, ambos detêm igualmente apenas 0,22\% dos municípios na faixa de 0,8-1,0 do IFDM. Na faixa de desenvolvimento moderado (0,6$0,8)$ estão $84,8 \%$ dos municípios do Centro-Oeste, seguido do Sul $(82,79 \%)$ e Sudeste $(79,14 \%)$, novamente Nordeste e Norte aparecem ambos em menor proporção nesta faixa (48,33\% e 38,33\% respectivamente).

Já na faixa do desenvolvimento regular o Norte se destaca, apresentando a maior frequência $(57,11 \%)$ de municípios, sendo seguido do Nordeste com $48,22 \%$. Para as demais regióes o Centro-Oeste detém 7,49\% dos casos na faixa $04-0,6$, o Sudeste $7,01 \%$ e o Sul com o menor percentual $(1,18 \%)$. Para o baixo desenvolvimento $(0,0-0,4)$ somente o Norte e o Nordeste detêm municípios nesta faixa, sendo de $1,11 \%$ e $0,33 \%$ respectivamente. 
Figura 03 - Índice Firjan de Desenvolvimento Municipal para o ano de 2016
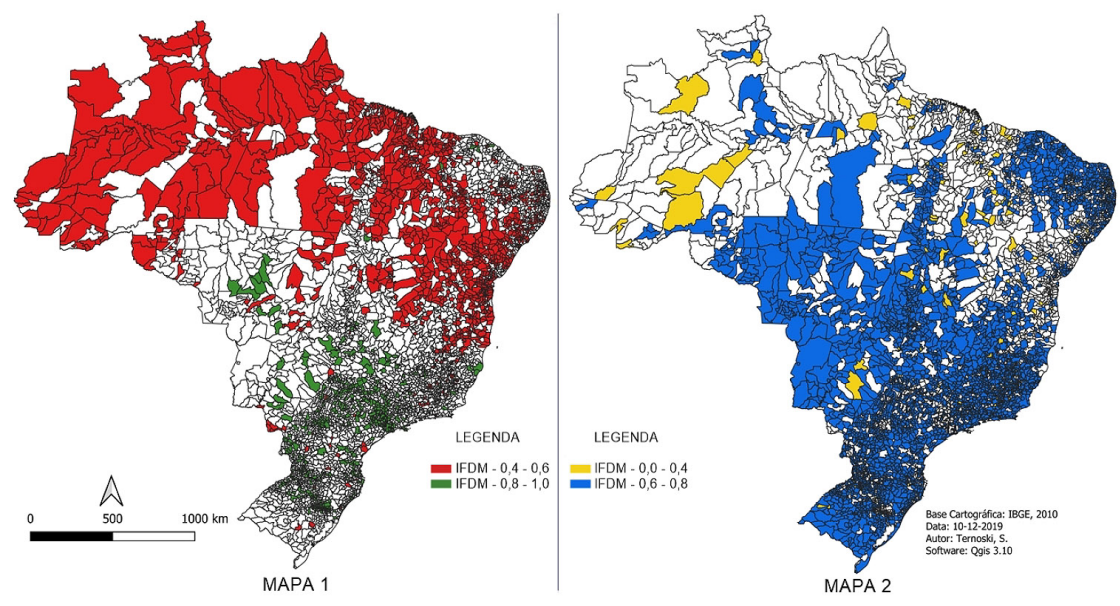

Fonte: Elaborado pelos autores a partir de Firjan (2019)

As Regióes Norte e Nordeste concentram todos os casos brasileiros de municípios tidos como de baixo desenvolvimento e $87,1 \%$ dos registros de casos com desenvolvimento regular. Já nas Regióes Sul e Sudeste é mais frequente que os municípios estejam classificados em desenvolvimento moderado $(61,6 \%)$ e alto $(92,10 \%$ de casos com índice entre 0,8 e 1,0$)$.

O comportamento do IFDM no tempo denota dois cenários distintos, conforme Figura 04, sendo: dimensôes com evolução positiva em todo o período (Índice Firjan de Desenvolvimento Municipal Educação - IFDM_E e Índice Firjan de Desenvolvimento Municipal - IFDM_S); e a dimensão Índice Firjan de Desenvolvimento Municipal Emprego e Renda - IFDM ER com variaçóes negativas em vários períodos, fruto da baixa atividade econômica já elencada na discussão do PIB, e que, também contribuiu para o menor desempenho do IFDM geral.

A maior variação acumulada foi observada na dimensão educação (IFDM-E), que evoluiu 35,09\%, crescendo a uma taxa média anual geométrica de $2,77 \%$, seguida desta dimensão, vem a saúde com crescimento médio de $2,48 \%$ ao ano e acumulado de $30,96 \%$ no período. Em termos da dimensão emprego e renda (IFDM-ER) o desempenho foi insatisfatório com variação negativa de $-10,75 \%$ no período $(-1,03 \%$ em média ao ano), reduzindo de 0,522 em 2005 para 0,466 em 2016, com uma forte queda $(-15,87 \%)$ entre $2014 / 2015$. O comportamento do IFDM-ER refletiu no indicador geral, cujo crescimento geométrico anual médio foi de 1,63\%, acumulando variação 19,4\% de 2005 a 2016. 
Figura 04 - Evolução do Índice Firjan de Desenvolvimento Municipal, período 2005/2016.

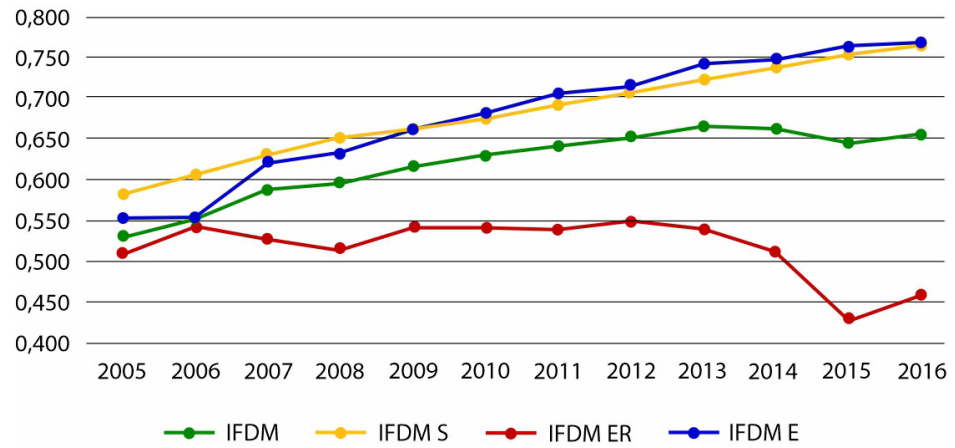

Fonte: Elaborado pelos autores a partir de Firjan (2019)

As constatações, feitas até o momento, indicam para um cenário tanto de concentração de riquezas como do desenvolvimento em favor de algumas regiôes. É preciso ainda avançar da descrição das demais variáveis objeto do estudo, assim a Figura 05 apresenta as políticas de combate à pobreza, sendo uma política distributiva (BPC) e uma política redistributiva (PBF).

Para o BPC os repasses estão separados em duas modalidades, sendo: as concessões aos idosos e os repasses aos deficientes. Em ambos os casos não foram verificadas retrações nos volumes destes benefícios para o período analisado, no acumulado o BPC cresceu 224,85\% entre 2005 e 2016, com média anual geométrica de $11,52 \%$ para o benefício aos deficientes e $11,05 \%$ aos idosos.

Figura 05 - Valores repassados aos municípios com BPC e PBF, período 2005/2016

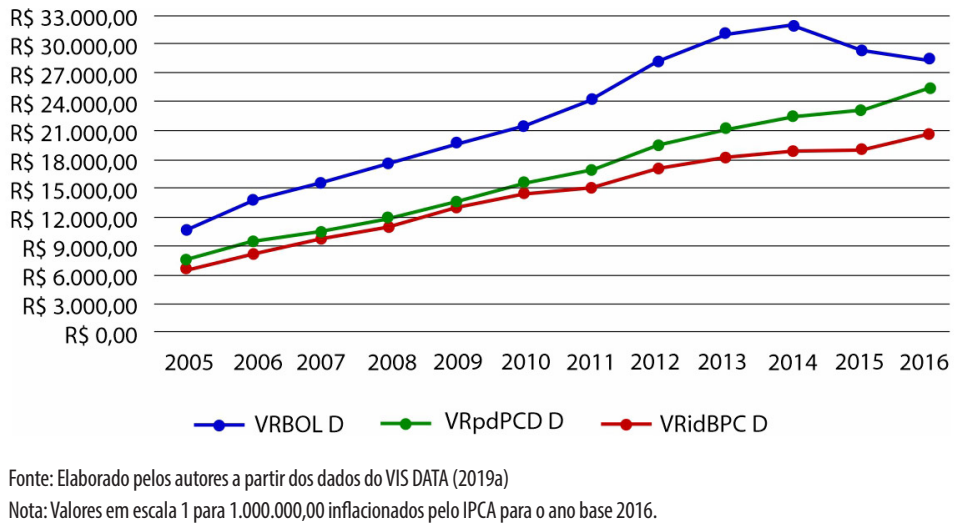


Quanto a PBF, o comportamento dos dados indica crescimento no montante repassado entre 2005 e 2014, com média geométrica anual de 12,91\%. Já entre 2014 e 2016 os repasses apresentaram uma retração média de 5,59\% ao ano, isso fez com que a evolução acumulada do período fechasse em $9,3 \%$.

Outra política redistributiva é a Previdência Social, Figura 06, com crescimento médio anual de 5,53\%, acumulando um aumento de $80,87 \%$ nos valores repassados, já as arrecadações, cresceram em média 3,01\% ao ano (acumulado de 38,63\%). Nota-se em relação às arrecadações que até $2012 \mathrm{a}$ média anual era de $8,13 \%$ ao ano, superior à média de pagamentos $(5,53 \%$ ao ano), mas, despencou após 2013, com redução geométrica média de $-5,37 \%$ ao ano, agravando o déficit e a trajetória decrescente, mais acentuada, do saldo da previdência.

Figura 06 - Despesas, arrecadações e o saldo da Previdência Social, período 2005/2016.

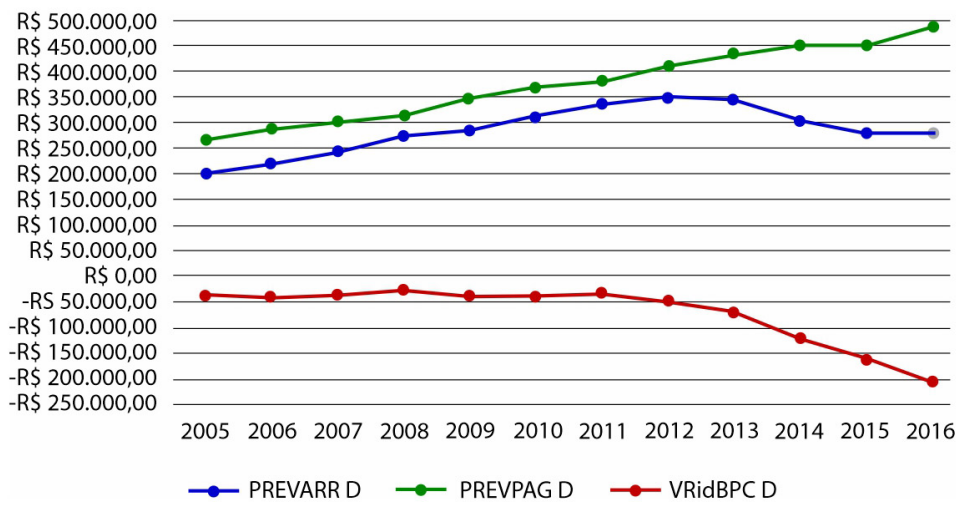

Nota: Valores em escala 1 para 1.000.000,00, inflacionados pelo IPCA para o ano base 2016

Fonte: Elaborado pelos autores a partir dos dados da Secretaria de Previdência (2019)

Por fim, o comportamento das outras três políticas redistributivas que são: o FPM; FUNDEB mais FUNDEF e o ITR, estão representados na Figura 07, a qual empregou escalas diferenciadas para melhor apresentação gráfica (ver nota). Os dados do FPM demonstram que no acumulado os repasses aumentaram $58,95 \%$, com um crescimento geométrico médio de 4,3\%, foram observadas retrações nos repasses entre 2008/2009; 2011/2012 e $2014 / 2015$. 
Figura 07 - Repasses aos municípios comFPM, FUNDEB+FUNDEF e ITR, período 2005/2016.

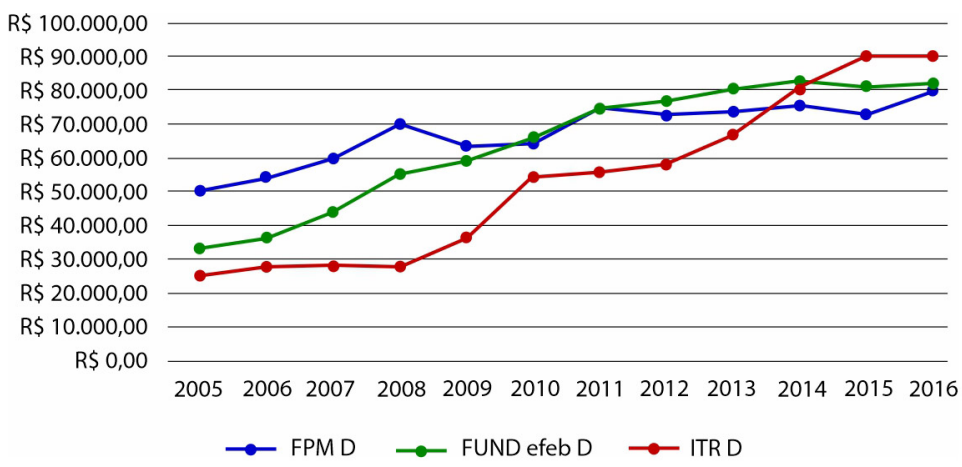

Nota: Valores em escala 1 para 1.000.000,00 para os dados do FPM e FUNDEB+FUNDEF e escala 1 para 10.000,00 para o ITR. Os valores foram inflacionados pelo IPCA para 0 ano base 2016.

Fonte: Elaborado pelos autores a partir dos dados do Tesouro Nacional (2019)

Para o FUNDEB mais FUNDEF houve crescimento acumulado de $145,47 \%$, com apenas o período de 2014 a 2015 de retração, o que caracterizou um crescimento anual médio de $8,51 \%$. Já o ITR acumulou crescimento de $254,83 \%$, com média geométrica de $12,2 \%$ ao ano, e apenas dois períodos de retração (2007/2008 e 2015/2016).

Vale ainda uma última análise sobre o comportamento populacional do período, o qual, segundo dados do VIS DATA (2019b) apresentou crescimento acumulado entre 2005 e 2016 de 11,91\% e média anual geométrica de 1,03\%, com um período (2006-2007) de retração da população estimada. A população variou de aproximadamente 184,2 milhôes de pessoas em 2005 para 206,1 milhóes em 2016. Realizada a etapa descritiva do comportamento das variáveis no tempo, o tópico seguinte estabelece a relação probabilística entre estas.

\section{ANÁLISE INFERENCIAL DO EFEITO DAS POLÍTICAS PÚBLICAS SOBRE O PRODUTO INTERNO BRUTO - PIB E O ÍNDICE FIRJAN DE DESENVOLVIMENTO MUNICIPAL - IFDM}

A análise desta seção considera a aplicação do modelo econométrico com dados em painel sobre as variáveis de interesse descritas na equação 01 da metodologia. O resultado da inferência entre as políticas públicas, o PIB e o IFDM considera inicialmente um cenário macro de análise (Tabela 01), que indica para a existência de efeito significativo a $1 \%$ de todas as variáveis explicativas, exceto de $\operatorname{lnFBBOL}$ no modelo do IFDM (não significativa). 
A relação entre as variáveis foi, em sua maioria, de efeito positivo, onde o aumento do repasse gera aumento no IFDM e no $\ln P I B$ e vice-versa. A exceção das variáveis $\ln N P B P C$; $\operatorname{lnITR}$; $\ln P O P$ no modelo do IFDM e, do $\ln F B B O L$ e $\ln N P B P C$, no modelo do $\ln P I B$, cujo aumento gera efeito inverso (redução) nos indicadores de riqueza e qualidade de vida.

As políticas objeto de análise, já estão consolidadas, cujo policy cycle se encontra na etapa de avaliação. Neste ponto, vale um parêntese para esclarecer sobre os ciclos de uma política (policy cycle). Em Souza (2006); Baptista e Rezende (2015); Heidemann (2009), Dye (2009), Raeder (2014) e Frey (2000), encontra-se uma definição, com pequenas variaçóes entre si, que aponta que o ciclo da política inicia-se na identificação dos problemas que norteiam a agenda de governo (influenciados nas arenas sociais), seguido da elaboração ou formulação, e a da implementação, por fim, ocorre a etapa de avaliação e eventuais correçôes da política.

Mas, é preciso relativizar o entendimento sobre a etapa de avaliação, a qual pode ser realizada também ao longo das etapas anteriores, sem necessariamente estar consolidada para que seja avaliada. Entretanto, especificamente as políticas tratadas neste estudo já estão na fase de avaliação (policy cycle), uma vez que já estão consolidadas.

Os resultados, apresentados na Tabela 01, para uma análise de efeito parcial, indicam que a cada variação de $1 \%$ nos repasses do $\ln B P C$ (política distributiva) tem-se uma variação de 0,00079 pontos no IFDM, e de 0,2913\% no $\ln P I B$, existindo, portanto, relação positiva. Como os dados do PIB foram logaritmizados, a aplicação do antilog permite medir em termos monetários, assim, o aumento (redução) de $\mathrm{R} \$ 1,00$ nos repasses do BPC gera um efeito de aumento (redução) de R \$ 1,34 no PIB.

Nesta mesma linha Neri et al. (2013), ao analisar o efeito multiplicador do BPC sobre o PIB, encontrou relação um pouco menor $(\mathrm{R} \$ 1,19)$ ao usar dados da Pesquisa de Orçamentos Familiares (POF) de 2008-2009. Já Mostafa et al. (2010), considerando a Pesquisa Nacional por Amostra de Domicílios - PNAD para 2006 e a POF de 2002-2003, estimou em 1,38\% este efeito multiplicador do BPC sobre o PIB, muito próximo ao encontrado neste estudo ( $\mathrm{R} \$ 1,34)$. Vale ponderar, nesta comparação, que as pesquisas citadas possuem metodologias específicas quanto ao período temporal e as entidades acompanhadas.

Para o número de beneficiários, constatou-se efeito inverso, onde o aumento de $1 \%$ dos beneficiários que acessam o BPC leva aredução de 0,00086 pontos no IFDM e, 0,299\% no InPIB. Massuda et al (2019) também encontrou relação entre o maior contingente de beneficiários do BPC com o menor índice de desenvolvimento humano, o que reafirma o resultado 
exposto, indicando que este aumento de beneficiários (famílias carentes), está relacionado aos municípios mais pobres e com menor qualidade de vida.

Tabela 01 - Modelo econométrico entre as variáveis explicativas (políticas públicas) sobre as dependentes IFDM e o logaritmo do PIB para os municípios brasileiros

\begin{tabular}{|c|c|c|c|c|c|c|c|}
\hline \multicolumn{8}{|c|}{ Modelo de Efeitos Fixos para os municípios brasileiros } \\
\hline \multicolumn{4}{|c|}{ Variável dependente: IFDM } & \multicolumn{4}{|c|}{ Variável dependente: $\ln P I B$} \\
\hline Variáveis & Coeficiente & P-valor & Sig. & Variáveis & Coeficiente & P-valor & Sig. \\
\hline Constante & $-1,34364$ & 0,00000 & $\mathrm{~S}$ & Constante & 6,2425 & 0,0000 & $\mathrm{~S}$ \\
\hline $\ln N P B P C$ & $-0,08632$ & 0,00000 & S & $\ln N P B P C$ & $-0,2993$ & 0,0000 & S \\
\hline $\operatorname{lnVRBPC_{D}}$ & 0,07872 & 0,00000 & s & $\operatorname{lnVRBP} C_{D}$ & 0,2913 & 0,0000 & s \\
\hline $\operatorname{lnVRBOL_{D}}$ & 0,01784 & 0,00000 & S & $\operatorname{lnVRBOL_{D}}$ & 0,1300 & 0,0000 & s \\
\hline $\ln F B B O L$ & 0,00141 & 0,59919 & NS & $\ln F B B O \bar{L}$ & $-0,1275$ & 0,0000 & s \\
\hline $\ln P R E V A R R_{D}$ & 0,00413 & 0,00000 & s & $\operatorname{PREVARR}_{D}$ & 0,0127 & 0,0000 & S \\
\hline $\ln P R E V P A G_{D}$ & 0,03183 & 0,00000 & s & $P R E V P A G_{D}$ & 0,1713 & 0,0000 & s \\
\hline $\ln F P M_{D}$ & 0,03586 & 0,00000 & s & $\ln F P M_{D}$ & 0,2900 & 0,0000 & s \\
\hline $\operatorname{lnFUNDefeb_{D}}$ & 0,01240 & 0,00007 & S & $\operatorname{lnFUNDefeb_{D}}$ & 0,0708 & 0,0000 & s \\
\hline lnITR & $-0,00670$ & 0,00000 & s & $\operatorname{lnITR}$ & 0,0206 & 0,0000 & s \\
\hline $\ln P O P$ & $-0,02666$ & 0,00000 & S & $\ln P O P$ & 0,0577 & 0,0000 & s \\
\hline
\end{tabular}

Fonte: Resultados do Modelo

Seguindo para a relação das políticas redistributivas, verifica-se que entre a PBF e o IFDM tem-se a existência de relação positiva, onde cada $1 \%$ de aumento (diminuição) do repasse gera aumento (diminuição) de 0,00018 pontos no IFDM, reforçando que a PBF contribui na melhoria deste indicador.

Sobre a riqueza $(\ln P I B)$, a PBF também exerce influência positiva, cada variação de $1 \%$ nos repasses do benefício aos municípios gera variação de 0,13\% no lnPIB. Em termos monetários, o aumento (diminuição) de R $\$ 1,00$ nos repasses do programa, eleva (diminui) em $\mathrm{R} \$ 1,14$ o PIB, comprovando que no cenário macro a política pública redistributiva do Bolsa Família cria um efeito multiplicador na riqueza dos municípios.

Citando novamente Neri et al. (2013) e Mostafa et al. (2010) estes trabalhos encontraram maior efeito multiplicador da relação entre o PBF e o PIB ( $R \$ 1,78$ e 1,44\% respectivamente), superiores aos $R \$ 1,14$ desta pesquisa, mas destaca-se que o presente estudo trata de um período de tempo maior e envolve como entidades todos os municípios brasileiros. 
Quanto aos beneficiários do PBF a relação é inversa (negativa), visto que o aumento (diminuição) de $1 \%$ no $\ln F B B O L$ gera a diminuição (aumento) de $0,127 \%$ no $\ln P I B$. Esta relação não foi significativa para o IFDM, mas, o efeito inverso encontrado é semelhante ao observado no efeito do BPC.

Os dados do VIS DATA (2019a) sobre os repasses do PBF e inflacionados pelo IPCA para dezembro de 2018 indicam que entre 2015-2018 houve redução geométrica média de 1,828\% ao ano nos repasses do programa. Aplicando aos dados do modelo, percebe-se uma possibilidade de impacto negativo de aproximadamente $0,24 \%$ no crescimento do PIB dos municípios brasileiros, para os próximos anos, mantendo as demais variáveis constantes.

Outra linha de análise é a Previdência Social, importante em um cenário de reformas e projeçốes de economicidade nestes repasses. Nota-se efeito positivo quanto a $\ln P R E V A R R$, onde o aumento de $1 \%$ nas arrecadaçóes gera aumento de 0,00004 pontos no Índice Firjan de Desenvolvimento Municipal (IFDM) e de 0,0127\% no $\ln P I B$ dos municípios e vice-versa. Em termos de repasses, os efeitos também são positivos e a cada variação de $1 \%$ em $\ln P R E P A G$ tem-se uma variação de 0,00032 pontos no IFDM e de $0,1713 \%$ no $\ln P I B$. Ou ainda, a cada $\mathrm{R} \$ 1,00$ a mais nos pagamentos previdenciários o efeito sobre o PIB dos municípios é de R \$1,187.

Comparativamente aos resultados de Neri et al. (2013) e Mostafa et al. (2010), os achados desta pesquisa estão em uma posição intermediária aos achados das pesquisas citadas. Neri et al. (2013) estimou efeito sobre o PIB de $\mathrm{R} \$ 0,52$ a cada um real de aumento dos repasses com o Regime Geral da Previdência Social, já Mostafa et al. (2010) aponta um efeito multiplicador de $1,23 \%$, mais próximo dos $\mathrm{R} \$ 1,187$ aqui estimados.

O resultado encontrado é de grande relevância em um cenário de economicidade nos repasses previdenciários projetados em 800 bilhóes nos próximos 10 anos. Avaliando a economia da reforma da previdência de 2019 frente aos dados do modelo, conclui-se para uma redução de aproximadamente 949,5 bilhões no PIB dos municípios em 10 anos, equivalente a uma diferença (perda) de 149,5 bilhôes aproximadamente entre a economicidade da reforma e o efeito de desaceleração do PIB, se mantidas as demais variáveis constantes.

Para além dos resultados observados, vale pontuar que estes repasses contribuem no dinamismo econômico dos municípios, fomentando o emprego e a renda e, consequentemente, novas arrecadações de impostos (campo para pesquisas futuras). É um cenário da policy networks de embate contrário as políticas sociais, apontado em Frey (2000), e que se figura na atual realidade brasileira, intensificada após 2016, mediante disputa de recursos escassos pelos atores sociais. Cria-se uma política de lealdade (policy lealdades), visível 
quando o foco é reduzir as políticas redistributivas de cunho social, cenário presente nos dados decrescentes de repasses do PBF e na reforma da previdência.

Aliado aos resultados já apresentados, Soares et al. (2006) e Hoffmann (2010) entendem que o BPC, PBF e Previdência Social são políticas de grande relevância na redução da desigualdade entre as famílias. Já Castro (2012) afirma que estas políticas públicas ampliam o canal da demanda agregada fortalecendo os mercados (efeito multiplicador da renda), e com isso, alavancando o desenvolvimento nacional.

Os efeitos da previdência são discutidos também em Reis, Silveira e Braga (2013) para o cenário do desenvolvimento socioeconômico dos municípios mineiros, os autores concluem que a previdência afeta positivamente os municípios de pequeno porte. Já Kerstenetzky (2009) afirma que o PBF é fundamental na redução das privações, se aproximando assim da concepção de desenvolvimento de Sen (2000).

O estudo de Soares et al. (2006) avaliou o efeito de um rol de transferências sociais na redução da desigualdade e pobreza junto à PNAD entre 1995 a 2004. Concluíram que os programas de transferências sociais minimizam as situações de pobreza, sobretudo, o PBF e o BPC são responsáveis por uma queda de $28 \%$ no índice de Gini, apesar de representarem apenas $0,82 \%$ da renda das famílias da PNAD. Também verificaram que as pensóes e aposentadorias oficiais reduzem o Gini em 32\%, impactando na redução da desigualdade, um menor efeito se comparado ao BPC e ao PBF, já que as aposentadorias e pensôes correspondem a $4,6 \%$ da renda total das famílias.

Hoffmann (2010, p. 661) ambém encontrou efeitos semelhantes das aposentadorias, BPC e PBF na minimização da desigualdade ao avaliar os dados da POF de 2002/03 e de 2008/09. O autor constatou que existe uma pequena progressividade na renda familiar quando relacionada aos recebimentos de pensões e aposentadorias do regime geral da Previdência Social, mas a maior progressividade está nos programas sociais, sobretudo, o Bolsa Família, que segundo os dados "representa $12,1 \%$ da renda dos $10 \%$ mais pobres da população".

Ainda no campo das políticas redistributivas vale prosseguir com a análise das transferências constitucionais repassadas aos municípios pela União. Os efeitos sobre o IFDM indicam que, a cada variação de $1 \%$ no $\ln F P M$, no $\ln F U N D \_e f e b$ e no $\ln I T R$ geram respectivamente variação de 0,00036, 0,00012 e -0,00007 pontos no IFDM. Na via da riqueza as variaçóes de $1 \%$ no $\ln F P M$, no $\operatorname{lnFUND\_ efeb~e~no~} \operatorname{lnITR}$ ocasionam variaçôes respectivamente de $0,29 \%, 0,071 \%$ e $0,021 \%$ no $\ln P I B$. 
Analisando em termos reais, conclui-se que cada $R \$ 1,00$ de aumento no repasse das transferências constitucionais gera aumento no PIB de R \$ 1,34 na relação com o FPM, em R $\$ 1,07$ para os repasses do FUNDEF+ FUNDEB e de R \$ 1,02 para o ITR. Tarda e Rodrigues (2015) aplicaram 13 especificaçôes de modelos em dados de 2007 para 90 cidades da região de Campinas, concluíram que os investimentos em educação são promotores do crescimento do PIB, embora nesta análise o objeto não foi necessariamente o FUNDEF e FUNDEB.

Resende et al. (2015), embora avaliando o efeito de outros fundos constitucionais empregaram modelos em painel de efeitos fixos entre 1999 a 2011 em um total de 2.877 municípios. As constatações indicam para efeito positivo dos fundos constitucionais no PIB per capita, mas também, identificaram efeitos que variam de acordo com a região e com o município, reforçando a necessidade de avançar a discussão sobre os aspectos regionais.

Por fim, anterior à análise regionalizada, vale verificar o efeito da variável população, os resultados indicam que o aumento de $1 \%$ em $\ln P O P$ provoca uma redução de -0,00027 pontos no IFDM, revelando que os municípios não tem conseguido propiciar meios para a qualidade de vida na mesma proporção do aumento da população. Em termos do $\ln P I B$ nota-se um aumento $0,057 \%$, indicando que cada novo habitante eleva em $\mathrm{R} \$ 1,06$ o PIB. Uma relação que demonstra que nem sempre a expansão de população e de riqueza leva propriamente a melhorias dos indicadores de desenvolvimento.

Regionalizando a análise o modelo da equação 01 foi replicado para 20 (vinte) novos cenários. As regionalidades consideradas são: as cinco grandes regiôes brasileiras, (Centro-Oeste, Nordeste, Norte, Sudeste e Sul); somente municípios que fazem parte da Amazônia Legal; municípios do semiárido brasileiro; cidades-região de São Paulo; municípios com população urbana (Censo IBGE 2010) maior que 50\%; e municípios com população rural superior a 50\%, os resultados estão expressos na Tabela 02 .

Os dados foram analisados por política e região em termos do maior e menor efeito, as demais relações podem ser consultadas na Tabela 02. Quanto ao BPC, os efeitos são positivos sobre a qualidade de vida, com maior reflexo no Centro-Oeste, onde cada variação de $1 \%$ no $\ln V R B P C_{D}$ gera aumento de 0,0013 pontos no índice, já no Sudeste ocorre o menor reflexo com 0,00064 pontos. Sobre a riqueza, o Sudeste apresenta a maior resposta, onde cada variação de $\mathrm{R} \$ 1,00$ no repasse reflete em $\mathrm{R} \$ 1,39$ no PIB, e o Centro-Oeste o menor efeito $(\mathrm{R} \$ 1,20)$. 
Tabela 02 - Modelo regionalizado aos municípios das cinco regiões brasileira, da Amazônia legal, do semiárido, das cidades-região de São Paulo, urbanos e rurais.

Regionalidades e a relação entre as políticas públicas e o IFDM

\begin{tabular}{|c|c|c|c|c|c|c|c|c|c|c|}
\hline Parâmetros & $\mathrm{CO}$ & NE & NO & SE & SUL & Amz & Sar & CRsp & Pop urb & PopRur \\
\hline Constante & $-1,0717$ & $-1,9565$ & $-1,0600$ & $-0,7896$ & $-0,4156$ & $-1,2671$ & $-2,2703$ & 0,6541 & $-1,2220$ & $-1,7956$ \\
\hline $\ln N P B P C$ & $-0,1447$ & $-0,0966$ & $-0,0612$ & $-0,0796$ & $-0,0693$ & $-0,0953$ & $-0,1004$ & $-0,0167$ & $-0,0867$ & $-0,0834$ \\
\hline $\ln V R B P C_{D}$ & 0,1338 & 0,1024 & 0,0872 & 0,0643 & 0,0812 & 0,1169 & 0,1058 & 0,0195 & 0,0804 & 0,0813 \\
\hline $\ln V R B O L_{D}$ & 0,0166 & 0,0352 & 0,0452 & 0,0159 & 0,0240 & 0,0406 & 0,0352 & 0,0280 & 0,0146 & 0,0409 \\
\hline $\operatorname{lnFBBOL}$ & $-0,0124$ & $-0,0376$ & $-0,0381$ & $-0,0042$ & $-0,0136$ & $-0,0384$ & $-0,0221$ & $-0,0222$ & 0,0035 & $-0,0182$ \\
\hline $\ln P R E V A R R_{D}$ & 0,0087 & 0,0026 & 0,0012 & 0,0053 & 0,0063 & 0,0025 & 0,0013 & 0,0105 & 0,0046 & 0,0019 \\
\hline $\ln P R E V P A G_{D}$ & 0,0075 & 0,0101 & 0,0027 & 0,0394 & $-0,0117$ & $-0,0097$ & 0,0216 & 0,0063 & 0,0283 & 0,0230 \\
\hline $\ln F P M_{D}$ & 0,0198 & 0,0194 & 0,0066 & 0,0230 & 0,0157 & 0,0179 & 0,0175 & $-0,0417$ & 0,0321 & 0,0525 \\
\hline $\ln F U N D e f e b_{D}$ & 0,0064 & 0,0624 & 0,0136 & 0,0031 & 0,0107 & 0,0180 & 0,0639 & 0,0187 & 0,0116 & 0,0184 \\
\hline lnITR & 0,0024 & $-0,0036$ & 0,0022 & $-0,0066$ & 0,0069 & 0,0004 & $-0,0037$ & $-0,0061$ & $-0,0058$ & $-0,0040$ \\
\hline $\ln P O P$ & $-0,0274$ & $-0,0227$ & $-0,0074$ & $-0,0315$ & $-0,0298$ & $-0,0147$ & $-0,0232$ & $-0,0157$ & $-0,0244$ & $-0,0346$ \\
\hline
\end{tabular}

Regionalidades e a relação entre as políticas públicas e o InPIB

\begin{tabular}{|c|c|c|c|c|c|c|c|c|c|c|}
\hline Parâmetros & $\mathrm{CO}$ & NE & NO & SE & SUL & Amz & Sar & CRsp & Popurb & Poprur \\
\hline Constante & 5,8912 & 7,7385 & 5,9611 & 7,5710 & 6,1017 & 5,1791 & 6,9346 & 10,9724 & 6,5399 & 4,7948 \\
\hline $\ln N P B P C$ & $-0,2249$ & $-0,2182$ & $-0,1404$ & $-0,3398$ & $-0,2632$ & $-0,2186$ & $-0,2121$ & $-0,2638$ & $-0,3021$ & $-0,2966$ \\
\hline $\ln V R B P C_{D}$ & 0,1827 & 0,2317 & 0,1040 & 0,3275 & 0,3039 & 0,1236 & 0,2432 & 0,2731 & 0,2930 & 0,3023 \\
\hline $\ln V R B O L_{D}$ & 0,1291 & 0,1350 & 0,2519 & 0,0802 & 0,1286 & 0,2812 & 0,1197 & 0,0753 & 0,1282 & 0,1396 \\
\hline $\ln F B B O L$ & $-0,1294$ & $-0,1330$ & $-0,2138$ & $-0,0772$ & $-0,1669$ & $-0,2524$ & $-0,0568$ & $-0,0714$ & $-0,1269$ & $-0,1340$ \\
\hline $\ln P R E V A R R_{D}$ & 0,0307 & 0,0046 & 0,0073 & 0,0217 & 0,0096 & 0,0051 & 0,0049 & 0,0056 & 0,0167 & 0,0009 \\
\hline $\ln P R E V P A G_{D}$ & 0,1876 & 0,1260 & 0,1417 & 0,1819 & 0,0546 & 0,2060 & 0,1122 & 0,2827 & 0,1846 & 0,1104 \\
\hline $\ln F P M_{D}$ & 0,3378 & 0,1136 & 0,2803 & 0,2546 & 0,3801 & 0,3001 & 0,1196 & 0,0583 & 0,2680 & 0,3736 \\
\hline $\ln F U N D$ efe $b_{D}$ & 0,0462 & 0,2207 & 0,1641 & 0,0404 & 0,0838 & 0,1349 & 0,2191 & 0,0687 & 0,0694 & 0,0764 \\
\hline InITR & 0,0931 & 0,0052 & 0,0148 & 0,0118 & 0,0530 & 0,0358 & 0,0071 & $-0,0350$ & 0,0211 & 0,0175 \\
\hline $\ln P O P$ & 0,0638 & 0,0482 & 0,0905 & 0,0290 & 0,0869 & 0,0584 & 0,0673 & 0,0128 & 0,0510 & 0,0983 \\
\hline
\end{tabular}

Nota: Parâmetros na cor vermelha não significativos ao nível mínimo de erro de 5\%; valores em azul significativos a 5\% e demais valores significativos a $1 \%$. Fonte: Resultados do Modelo.

No campo das políticas redistributivas, a relação do PBF sobre o desenvolvimento apresenta maior efeito no Norte, e menor nos municípios com predominância de população urbana. Nestes cenários uma variação de $1 \%$ no $\operatorname{lnVRBOL_{D}}$ leva a uma variação de 0,00045 e 0,00014 pontos no Índice Firjan de Desenvolvimento Municipal (IFDM), respectivamente. Para o $\ln P I B$, o maior efeito positivo é encontrado nos municípios da Amazônia Legal, $R \$ 1,32$ para cada $R \$ 1,00$ de variação na PBF, e o menor no Sudeste $(\mathrm{R} \$ 1,08)$. 
Os resultados estão condizentes com a literatura já discutida, reafirmando a relação positiva das políticas redistributivas na redução da desigualdade. Os efeitos são mais perceptíveis em regióes onde a desigualdade e a pobreza são mais acentuadas, nestes espaços, a política pública tem seus resultados potencializados, criando um efeito multiplicador na renda e nos processos de crescimento e de desenvolvimento.

Quanto à Previdência Social, os parâmetros estimados foram estatisticamente significativos apenas em três cenários: Sudeste, semiárido e população urbana. O maior efeito sobre o IFDM se deu no Sudeste $(0,00039$ pontos a cada $1 \%$ de variação no $\ln P R E V P A G_{D}$ ) e, o menor reflexo, no semiárido (0,000216 pontos). Para o $\ln P I B$ as cidades-região de São Paulo sentem mais os resultados ( $\mathrm{R} \$ 1,33$ a cada real), já os municípios de predominância rural possuem o menor reflexo $(\mathrm{R} \$ 1,12)$.

Para os repasses constitucionais nota-se que a variação de $1 \%$ no $\ln F P M_{D}$ gera o maior reflexo (positivo) nos municípios com predominância rural $(0,000525)$ e o menor, neste caso negativo, nas cidades-região de São Paulo (0,000417 pontos no índice). Quanto ao PIB, em todas as regióes o efeito do FPM foi positivo, sendo maior no Sul e com menor intensidade no Nordeste ( $\mathrm{R} \$ 1,46$ e $\mathrm{R} \$ 1,12$, respectivamente).

Em termos da variável lnFUNDefe $b_{D}(\mathrm{FUNDEF}+\mathrm{FUNDEB})$ os efeitos são positivos, e com maior impacto no Semiárido brasileiro (0,000639), e menor no cenário de predominância da população urbana $(0,000116$ pontos no IFDM). Para o PIB, o Nordeste reflete mais intensamente as variaçóes na riqueza $(\mathrm{R} \$ 1,25)$ e o Sudeste o menor efeito $(\mathrm{R} \$ 1,04)$.

O ITR apresenta efeitos que variam como positivos e negativos a depender da região. Sob o aspecto da qualidade de vida o cenário com maior reflexo é o Sul, com 0,000069 pontos no IFDM para cada 1\% de variação do repasse, já no Sudeste o menor efeito, inclusive negativo (-0,000066). No que se trata do PIB, o Centro-Oeste apresentou a maior resposta $(\mathrm{R} \$ 1,10$ a cada real de repasse do ITR), mas, o menor efeito é sobre as cidades-região de São Paulo (R \$ 0,97). Uma menor resposta nas cidades-região de São Paulo decorrente da menor participação do setor agropecuário na composição do PIB total, 0,36\% apenas no período como um todo, bem inferior aos 5,91\% de participação do setor na composição do PIB das demais regióes.

Por fim, ainda os dados da Tabela 02 relacionam dados populacionais e seus reflexos no indicador de qualidade de vida e de renda. Nota-se que para os municípios rurais a cada aumento de $1 \%$ da população, tem-se uma redução de 0,0000346 pontos no IFDM, já nos municípios da Amazônia Legal o aumento populacional contribui de forma positiva com o indicador de qualidade de vida $(0,000147$ pontos). 
Sobre o PIB o menor efeito do aumento populacional é sentido no Nordeste, onde cada habitante adicional eleva em R \$ 1,05 o PIB. Já nos municípios com predominância de população rural (maior resposta), cada novo habitante eleva em $\mathrm{R} \$ 1,10$ o PIB. Estes dados de contraste da população sobre o IFDM e PIB reafirmam a teoria, ao passo que o aumento populacional gera riquezas, mas não necessariamente melhoria da qualidade de vida.

As inferências indicam e reforçam a necessidade do olhar regional das políticas públicas, apesar de existirem feitos positivos no ambiente macro

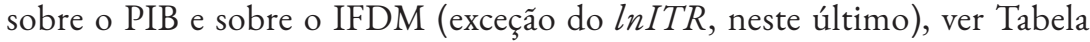
01, a proporção dos efeitos varia regionalmente de acordo com cada uma das políticas (Tabela 02). Por exemplo, o BPC é mais expressivo no PIB do Sudeste ( $\mathrm{R} \$ 1,39)$, um pouco acima dos $\mathrm{R} \$ 1,34$ observado no cenário geral, já a PBF possui maior resposta nos municípios da Amazônia Legal (R \$ 1,32), bem acima dos $\mathrm{R} \$ 1,14$ do cenário geral. Ainda neste comparativo a previdência impacta mais no PIB das cidades-região de São Paulo ( $\mathrm{R}$ 1,33), contra os $\mathrm{R} \$ 1,18$ do cenário macro.

Quanto aos repasses constitucionais os efeitos foram no cenário macro de $\mathrm{R} \$ 1,34, \mathrm{R} \$ 1,07$ e $\mathrm{R} \$ 1,02$ respectivamente para o FPM, FUNDEF+ FUNDEB, e ITR, mas regionalmente foram mais sentidos no Sul (R \$ $1,46)$ para o FPM, no Nordeste $(\mathrm{R} \$ 1,25)$ para o FUNDEF+FUNDEB e no Centro-Oeste $(\mathrm{R} \$ 1,10)$ para o ITR. O aumento populacional também reflete regionalmente, sendo que o PIB aumenta mais nos municípios rurais ( $\mathrm{R} \$ 1,10$ a cada novo habitante), contra os $\mathrm{R} \$ 1,06$ do cenário macro.

De maneira semelhante os efeitos sobre a qualidade de vida são diferenciados regionalmente se comparados a analise macro. O BPC gera 0,0013 pontos no IFDM no Centro-Oeste, e no cenário macro o reflexo é muito menor (0,00079). Já a PBF tem forte impacto no Nordeste $(0,00045)$, contra 0,00018 do contexto geral. O mesmo ocorre com a Previdência, que no cenário macro é pouco expressiva $(0,00004)$, mas, com maior efeito no Sudeste (0,00039).

Para o FPM os municípios rurais refletem 0,000525 pontos no IFDM, contra os 0,00036 do contexto macro. O FUNDEF+FUNDEB gera aumento de 0,00012 pontos no cenário macro do índice, contra 0,000639 do Semiárido. Quanto ao ITR tem-se variação negativa $(-0,00007)$ no cenário macro, mas efeito positivo no IFDM do Sul $(0,000069)$. A população também reflete regionalmente, reduzindo o índice em -0,00027 no cenário macro e em todas as demais regióes, mas, sendo a redução mais sentida nos municípios rurais $(-0,0000346)$.

A literatura em Theis e Galvão (2012), Sen (2000) e Resende et al. (2015) reforçam esta necessidade do olhar regional para entender a heterogeneidade 
dos contextos, e os diferentes efeitos de cada política. Azzoni et al. (2007) ao avaliar os efeitos da PBF sobre a renda e a desigualdade identificaram também respostas diferenciadas para cada região. Fato também identificado por Landim Junior (2009) ao encontrar respostas distintas de cada setor aos efeitos da PBF, sobretudo com maiores reflexos em regióes com maior desigualdade.

Tanto os dados do estudo como a literatura indicam que os efeitos macro produzem respostas divergentes da análise regionalizada. Logo, sugere-se que na etapa de formulação das políticas públicas sejam consideradas as espacialidades como forma de gerar resultados que minimizem as desigualdades, tanto de renda como de bem-estar social.

\section{CONSIDERAÇÕES FINAIS}

A finalidade em avaliar os reflexos das políticas públicas sobre os indicadores de riqueza e qualidade de vida é relevante em um cenário de questionamento, ataque às políticas públicas e o consequente desmonte do Estado. Por exemplo, dados do VIS DATA (2019a) inflacionados para 2018 demonstram que entre 2015-2018 houve uma redução média anual de 1,83\% nos repasses do Bolsa Família. Aliado a isso, a reforma da Previdência Social de 2019 prometeu uma economicidade de 800 bilhóes em 10 anos, conforme aponta a Agência Senado (2019).

É visível a relevância das políticas públicas na consolidação do Índice Firjan de Desenvolvimento Municipal (IFDM) e do Produto Interno Bruto (PIB) dos municípios brasileiros. A hipótese alternativa $\left(H_{1}\right)$ foi aceita para o cenário nacional indicando presença de efeito probabilístico positivo ou negativo das políticas sobre a riqueza e a qualidade de vida, mas, regionalmente foi parcialmente aceita, uma vez que determinadas políticas para determinadas regióes não foram significativas.

No cenário macro analisado o BPC e o FPM mais impactaram no PIB e no IFDM, e os menores reflexos são encontrados no efeito do ITR sobre o PIB e no efeito da população sobre o IFDM. Regionalmente, o FPM gera maiores respostas no Sul sobre o PIB e o FUNDEF+FUNDEB sobre o IFDM do Semiárido. A menor resposta é sentida tanto com o ITR em relação ao PIB nos municípios das cidades-região de São Paulo, como com a população com impacto negativo no IFDM dos municípios de predominância rural.

Nos modelos regionalizados o IFDM apresenta maior resposta no Centro-Oeste para o repasse do BPC, no Nordeste quanto a PBF, no Sudeste para a Previdência, nos municípios de predominância rural para o FPM, no Semiárido para o FUNDEF+FUNDEB e no Sul para a resposta ao ITR. Já 
em termos do PIB o BPC gera maiores respostas no Sudeste, a PBF nos municípios da Amazônia Legal, a Previdência nas cidades-região de São Paulo, o FPM no Sul, o FUNDEF+FUNDEB no Nordeste e o ITR no Centro-Oeste.

Vale ainda pontuar que nas regióes mais pobres e com menor indicador de qualidade de vida, como o Norte e Nordeste, que possuem maior frequência de municípios com menor PIB e IFDM, as políticas PBF e FUNDEF+FUNDEB foram as que mais auxiliaram estas regióes a superar a desigualdade, e a elevar a riqueza.

É evidente a relevância das políticas públicas (distributiva e redistributivas), demandando uma percepção acerca das regionalidades no sentido de potencializar seus efeitos. Geralmente, as decisóes são tomadas considerando o ótimo econômico, ao passo que deveriam também levar em consideração as arenas sociais e suas coalizóes de forças para determinar os rumos de uma política e os grupos/regiôes beneficiadas.

As limitações do estudo em termos do modelo e das variáveis decorre dos resultados restritivos devido a heterocedasticidade (teste de wald - comentários metodológicos), aliado ao número reduzido de variáveis (políticas) englobadas. É evidente que um modelo geral, ou mesmo que regionalizado nas grandes regióes, pode não registrar fielmente as particularidades de cada município, sugere-se estudos com maior delimitação espacial que captem estas especificidades municipais e das microrregióes.

A política em determinados ambientes encontra meios mais férteis para potencializar seus resultados, enquanto em outros ambientes, os resultados são menos efetivos. Cabe aos gestores públicos, considerar as espacialidades no sentido de propor políticas mais eficientes para cada região com o intuito de otimizar o recurso público e promover a equidade tanto da renda como do bem-estar social, ainda que, seja preciso relativizar esta afirmação, visto que, mesmo diante de políticas de cunho federal, dado a heterogeneidade dos municípios, muitos não dispóe dos meios (políticas) que permitam gerar o crescimento e o desenvolvimento.

\section{Notas}

${ }^{1}$ Coeficiente de Variação abaixo de 15\% indica homogeneidade na dispersão dos dados; entre 15\% e 30\% dispersão mediana; e acima de $30 \%$ alta dispersão. O CV das variáveis é: $\operatorname{IFDM}(19,24 \%) ; \ln P \operatorname{IB} B_{D}(7,53 \%) ; \operatorname{lnVRBPC_{D}}(12,18 \%)$; $\operatorname{lnNPBPC}(33,42 \%) ; \operatorname{lnVRBOL} L_{D}(9,82 \%) ; \quad \ln F B B O L(19,2 \%) ; \ln P R E V A R R_{D}(12,08 \%) ; \ln P R E V P A G_{D}(10,45 \%) ; \ln F P M_{D}$

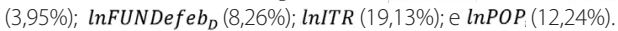

${ }^{2}$ Indica que a variância para $Y$ e $X$ é constante, neste caso, ao afirmar seu oposto (heterocedasticidade), os dados estariam mais dispersos em torno das projeções do modelo econométrico regredido.

${ }^{3} \mathrm{O}$ modelo Pooled desconsidera as dimensões de tempo e espaço, empilhando as observações e obtendo os estimadores da regressão, o Efeitos Fixos permite uma análise individual, tanto mantendo o coeficiente angular e variando os interceptos (embora invariante no tempo), como também, variações entre as entidades i e entre o tempo $t$, já o Efeito Aleatório considera o intercepto e o coeficiente angular variando entre os indivíduos e agregando a falta de conhecimento do modelo em um termo de erro combinado entre a série temporal e o corte transversal. 
O modelo mais apropriado considera os testes de Chow que verifica se ocorreu rompimento em uma tendência estável da série histórica, cujas hipóteses são: $H_{0}$ : hipótese nula (opção pelo Pooled); $H_{i}$ : hipótese alternativa (opção pelo efeito fixo), o teste de Breuch-Pagan que verifica se as variâncias de erro são iguais, sendo: $H_{0}$ : opção pelo Pooled; $H_{1}$ : opção pelo efeito aleatório, e por fim, o teste de Hausman que verifica a consistência do estimador, onde $H_{0}$ : opção aleatório; $H_{i}$ : opção efeito fixo.

\section{Referências}

ABRUCIO, F. L. A coordenação federativa no Brasil: a experiência do período FHC e os desafios do governo Lula. Revista de Sociologia e Política, Curitiba, n. 24, p. 41-67. 2005. Disponível em: https://bit.ly/330yuog. Acesso em: 04 ago. 2020.

AGÊNCIA SENADO. Aprovado o texto-base da reforma da Previdência. Publicado em 22 out. 2019. Disponível em: https://bit. ly/2EuYTmz. Acesso em: 18 dez. 2019.

AMARAL FILHO, J. A endogeneização no desenvolvimento econômico regional e local. Planejamento e Políticas Públicas, Brasília, IPEA, n. 23, p. 261-286, jun. 2001. Disponível em: https://bit.ly/3llesJK. Acesso em: 02 abr. 2020.

AZZONI, C. R., GUILHOTO, J. J. M., HADDAD, E. A., HEWINGS, G. J. D., LAES, M. A.; MOREIRA, G. R. C. Social policies, personal and regional income inequality in brazil: ani-oanalysis. In: LOVE, J. L.; BAER, W. (org.). Brazil under Lula. New York: PalgraveMacmillan. 2009.

BAPTISTA, T. W. F.; REZENDE, M. A ideia de ciclo na análise de políticas públicas. In: MATTOS, R. A.; BAPTISTA, T. W. F. (org.). Caminhos para análise das políticas de saúde, $1^{a}$ ed. Porto Alegre: Rede UNIDA, 2015. Disponível em: https://bit.ly/34tYWcR. Acesso em: 18 dez. 2019.

BARRETO, F. A. F. D. Crescimento econômico, pobreza e desigualdade de renda: o que sabemos sobre eles? Ensaio sobre pobreza 01. Fortaleza: Laboratório de estudos da pobreza/CAEN/UFC, dez. 2005. Disponível em: https://bit.ly/2yCwjju. Acesso em: 03 abr. 2020.

BECATTINI, G. Italian industrial districts: problems and perspectives. International Studies of Management \& Organization, 21(1), p. 83-90, 1991. Disponível em: https://bit. ly/3aRbu2R. Acesso em: 23 out. 2019.

BLANCHARD, O. Macroeconomia, 5 a ed. São Paulo: Pearson Prentice Hall, 2011.

BRASIL. Presidência da República. Casa Civil. Subchefia para Assuntos Jurídicos. Constituição da República Federativa do Brasil de 1988. Disponível em: https://bit. ly/2YX1sHt. Acesso em: 16 dez. 2019.

CASTRO, J. A. Política social e desenvolvimento no Brasil. Economia e Sociedade, Campinas, v. 21, p. 1011-1042, dez. 2012. Disponivel em https://bit.ly/3e10LEd. Acesso em: 18 dez. 2019.

CASTRO, J. A. Política social, distribuição de renda e crescimento econômico. In: FONSECA, A.; FAGNANI, E. Políticas sociais, desenvolvimento e cidadania. São Paulo: Editora Fundação Perseu Abramo, 2013. CAVALCANTE, L. R. M. T. Produção teórica em economia regional: uma proposta de sistematização. Revista Brasileira de Estudos Regionais e Urbanos, v. 2, n. 1, p. 9-32, fev. 2015. Disponível em: https://bit.ly/2UQfYkl. Acesso em: 07 abr. 2020.

DINIZ, C. C.; CROCCO M. Economia regional e urbana: contribuições teóricas recentes. Belo Horizonte: UFMG, 2006.

DRAIBE, S. A política social no período FHC e o sistema de proteção social. Tempo Social. São Paulo, v. 15, n. 2, p. 63-101. 2003. Disponível em: https://bit.ly/3i5kpjv. Acesso em: 04 ago. 2020.

DUARTE, C. M. R. Equidade na legislação: um princípio do sistema de saúde brasileiro? Ciência \& Saúde Coletiva, Rio de Janeiro, v. 5, n. 2, p. 443-463. 2000. Disponível em: https://bit.ly/2DlKqwr. Acesso em: 04 ago. 2020. 
DYE, T. R. Mapeamento dos modelos de análise de políticas públicas. In: HEIDEMANN, F. G.; SALM, J. F. (Org.). Políticas públicas e desenvolvimento: bases epistemológicas e modelos de análise. Brasília: UNB, 2009.

FEIJÓ, R. Desenvolvimento econômico: modelos, evidências, opções políticas e o caso brasileiro. São Paulo: Atlas, 2007.

FIRJAN. IFDM - Índice Firjan de Desenvolvimento Municipal. 2019. Disponível em: 〈https://bit.ly/3jojO3g $\rangle$. Acesso em: 11 dez. 2019.

FIRJAN. Metodologia. 2018. Disponível em: https://bit.ly/2RX7Mxp. Acesso em: $16 \mathrm{dez}$. 2019.

FREY, K. Políticas públicas: um debate conceitual e reflexões referentes à prática da análise de políticas públicas no Brasil. Planejamento e Políticas Públicas, $\mathrm{n}^{\circ} .21$, $\mathrm{p}$. 211-259, 2000. Disponível em: https://bit. ly/2JLGsg9. Acesso em: $18 \mathrm{dez} .2019$.

FURTADO, C. Pequena introdução ao desenvolvimento: enfoque interdisciplinar. São Paulo: Editora Nacional, 1980.

GELINSKI, C. R. O. G.; SEIBEL, E. J. Formulação de políticas públicas: questões metodológicas relevantes. Revista de Ciências Humanas. Florianópolis, v. 42, n 1 e 2, p. 227-240, maio 2008. Disponível em: https://bit.ly/2UNT8JE. Acesso em: 03 abr. 2020.

GUDYNAS, E. Buenvivir: Germinando alternativas al desarrollo. Revista América Latina en Movimiento, $n^{\circ}$ 462, año XXXV, II época, p. 1-20, fev. 2011. disponível em: https://bit.ly/34hDppi. Acesso em: 14 jan. 2020.

GUJARATI, D. Econometria Básica, $4^{\mathrm{a}}$ ed. Rio de Janeiro: Elsevier, 2006.

HEIDEMANN, F. G.; SALM, J. F. (Org.). Políticas públicas e desenvolvimento: bases epistemológicas e modelos de análise. Brasília: UNB, 2009.

HOFFMANN, R. Desigualdade da renda e das despesas per capita no Brasil, em
2002-2003 e 2008-2009, e avaliação do grau de progressividade ou regressividade de parcelas da renda familiar. Economia e Sociedade, Campinas, v. 19, nº 3, p. 647661, dez. 2010. Disponível em: https://bit. ly/2VgaJea. Acesso em: 06 abr. 2020.

IBGE - Instituto Brasileiro de Geografia e Estatística. Nota metodológica da série do PIB dos Municípios: Referência 2010. Versão 1, set. 2015. Disponível em: https://bit. ly/34sdOZe. Acesso em: 16 dez. 2019.

IBGE - Instituto Brasileiro de Geografia e Estatística. Produto Interno Bruto dos Municípios. 2019a. Disponível em: https:// bit.ly/2scUIch. Acesso em: 11 dez. 2019. IBGE - Instituto Brasileiro de Geografia e Estatística. Estimativas da População. 2019b. Disponível em: https://bit. ly/34mwEoq. Acesso em: $11 \mathrm{dez} .2019$. IBGE - Instituto Brasileiro de Geografia e Estatística. IPCA - Índice Nacional de Preços ao Consumidor Amplo. 2019c. Disponível em: https://bit.ly/2LG77ft. Acesso em: 19 dez. 2019.

IPEA - Instituto de Pesquisa Econômica Aplicada. Avaliação de políticas públicas: guia prático de análise ex ante, vol. 1. Casa Civil da Presidência da República. Brasília: Ipea, 2018. Disponível em: https://bit. ly/2UOFy91. Acesso em: 03 abr. 2020.

KERSTENETZKY, C. L. Redistribuição e desenvolvimento? A economia política do programa bolsa família. Dados, Rio de Janeiro, v. 52, nº. 1, p. 53-83, mar. 2009. Disponível em: https://bit.ly/39RBeKq. Acesso em: 03 abr. 2020.

LANDIM JUNIOR, P. H. Relatório Final: os efeitos do programa bolsa família sobre a economia dos municípios brasileiros. São Paulo: Insper - Instituto de Ensino e Pesquisa. Disponível em: https://bit. ly/3aOQlgD. Acesso em: 15 mai. 2020.

LANZARA, A. P. Ativismo burocrático, políticas sociais intersetoriais e os desafios da inclusão produtiva no Brasil. Desenvolvimento em Debate. v. 4, $\mathrm{n}^{\circ}$. 2, p. 63-81, 2016. Disponível em: https://bit. ly/34ik5s8. Acesso em: 03 abr. 2020. 
LOURENÇO, M. S. Políticas públicas e desenvolvimento. In: SILVA, C. L.; MENDES, J. T. G. (Org.). Reflexões sobre o Desenvolvimento Sustentável: Agentes e interações sob a ótica multidisciplinar. Petrópolis: Vozes, 2005.

LOWI, T. Four Systems of Policy, Politics, and Choice. Public Administration Review, v. 32, n 4, jul/aug.p.298-310.1972. Disponível em: https://bit.ly/3frFRxD. Acesso em: 18 dez.2019.

MAGALHAES, J. P. A. Nova estratégia de desenvolvimento para o Brasil: um enfoque de longo prazo. Revista de Economia Política. São Paulo, v. 26, nº. 2, p. 86-202, jun. 2006. Disponível em: https://bit. ly/2xerYTc. Acesso em: 03 abr. 2020.

MARINI, M. J.; SILVA, C. L.; NASCIMENTO, D. E.; STRAUHS, F. R. Avaliação da contribuição de arranjos produtivos locais para o desenvolvimento local. Biblio $3 \mathrm{~W}$ : Revista Bibliográfica de Geografía Y Ciencias Sociales, Barcelona, Vol. XVII, nº 996, 15 out. 2012. Disponível em: https://bit.ly/2JOLA3e. Acesso em: 02 abr. 2020.

MASSUDA, E. M.; RUDEY, E. L.; BERNUCI, M. P.; BERTOLINI, S. M. M. G.; ANTUNES, M. D.; ODA, F. H.; YAMAGUCHI, M. U. Distribuição do benefício de prestação continuada entre as regiões brasileiras. Revista Univap, São José dos Campos/SP, v. 25, n. 49, dez. 2019. Disponível em: https:// bit.ly/2LnN19k. Acesso em: 02 abr. 2020.

MEC - Ministério da Educação. Fundeb Apresentação. 2019. Disponível em: http:// portal.mec.gov.br/fundeb. Acesso em: 16 dez. 2019.

MEDEIROS, C. A. Distribuição de Renda como Política de Desenvolvimento.

Desenvolvimento em Debate. Rio de Janeiro: BNDES, 2002. Disponível em: https://bit. ly/3aSBN86. Acesso em: 03 abr. 2020.

MELAZZO, E. S. Problematizando o conceito de políticas públicas: desafios à análise à prática do planejamento e da gestão. Tópos, v. 4. nº 2, p. 9-32. 2010. Disponível em: 〈https://bit.ly/39WZWKQ〉. Acesso em: 04 ago. 2020.
MOSTAFA, J.; SOUZA, P. H. G. F.; VAZ, F. M. Efeitos econômicos do gasto social no Brasil. In: CASTRO, J. A.; FERREIRA, H. R. S.; CAMPOS, A. G.; RIBEIRO, J. A. (Org.). Perspectivas da política social no Brasil. Brasília: Ipea, 2010.

NACIONES UNIDAS. Asamblea General. Desarrollo y cooperacion Económica Internacional: medio ambiente. 4 agosto 1987. 〈https://bit.ly/35CGRLR >. Acesso em: 05 mai. 2020.

NERI, M. C.; VAZ, F. M.; SOUZA, P. H. G. F. Efeitos macroeconômicos do programa Bolsa Família: uma análise comparativa das transferências sociais. In: CAMPELLO, T.; NERI, M. C. (Org.) Programa Bolsa Família: uma década de inclusão e cidadania, Brasília: Ipea, 2013.

PREBISCH, R. Por uma dinâmica do desenvolvimento latino-americano. In: BIELSCHOWSKY, R. (Org.). Cinquenta anos de pensamento na Cepal. Rio de Janeiro: Record, 2000. Disponível em: <https://bit. ly/2JLpwpU〉. Acesso em: 03 abr. 2020.

RAEDER, S. Ciclo de Políticas: uma abordagem integradora dos modelos para análise de políticas públicas. Perspectivas em Políticas Públicas. Belo Horizonte, v. VII, $n^{\circ}$ 13, p. 121-146, jan/jun 2014. Disponível em: 〈https://bit.ly/2yCDPLe〉. Acesso em: 18 dez. 2019.

REIS, P. R. C.; SILVEIRA, S. F. R.; BRAGA, M. J. Previdência social e desenvolvimento socioeconômico: impactos nos municípios de pequeno porte de Minas Gerais. Revista de Administração Pública, Rio de Janeiro, v. 47, n. 3, p. 623-646, jun. 2013. Disponível em: 〈https://bit.ly/39XldTq . Acesso em: 18 dez. 2019.

RESENDE, G. M.; SILVA, D. F. C.; SILVA FILHO, L. A. Avaliação dos fundos constitucionais de financiamento do Nordeste, do Norte e do Centro-Oeste: Uma análise por tipologia da política nacional de desenvolvimento regional entre 1999 e 2011. Texto para Discussão 2145. Instituto de Pesquisa Econômica Aplicada, Rio de Janeiro: Ipea, 2015. 
ROTTA, E.; REIS, C. N. Desenvolvimento e políticas sociais: uma relação necessária. Revista Textos \& Contextos. Porto Alegre, v. $6 n^{\circ}$. 2, p. 314-334, jul./dez. 2007. Disponível em: 〈https://bit.ly/2UP3ZDa $\rangle$. Acesso em: O3 abr. 2020.

SACHS, I. Estratégias de Transição para o Século XXI. In: RAYNAUT, C.; ZANONI, M. Cadernos de Desenvolvimento e Meio Ambiente. $\mathrm{n}^{\circ}$. 1, Curitiba: Editora UFPR, 1994.

SCHIMITZ, H.; NADVI, K. Clustering and Industrialization: Introduction. World Development, v. 27, ed. 9, p. 1503-1514, set. 1999. Disponível em: <https://bit. ly/2UNSopw $>$. Acesso em: 07 abr. 2020.

SCHNEIDER, S.; ESCHER, F. A contribuição de Karl Polanyi para a sociologia do desenvolvimento rural. Sociologias, Porto Alegre, v. 13, n. 27, p. 180-219, ago. 2011. Disponivel em: 〈https://bit.ly/2V8cBE4〉. Acesso em: 28 out. 2019.

SECCHI, L. Políticas públicas: conceitos, esquemas de análise, casos práticos. 2. ed. São Paulo: Cengage Learning, 2013. SECRETARIA DE PREVIDÊNCIA Ministério da Economia. Estatísticas Municipais 2000 a 2017. 2019. Disponível em: 〈https://bit.ly/2PyHEWE〉. Acesso em: 11 dez. 2019.

SEN, A. K. Desenvolvimento como Liberdade. São Paulo: Companhia das Letras. 2000.

SOARES; F. V.; SOARES, S.; MEDEIROS, M.; OSÓRIO, R. G. Programas de Transferência de Renda no Brasil. Impactos sobre a Desigualdade. Texto para Discussão n ${ }^{\circ} 1228$. IPEA - Instituto de Pesquisa Econômica Aplicada, Brasília, outubro 2006.

Disponível em: 〈https://bit.ly/3aTCcHc〉. Acesso em: 06 abr. 2020.

SOUZA, C. Políticas Públicas: Uma revisão da literatura. Sociologias (UFRGS), Porto Alegre, v. 8, n. 16, p. 20-45, 2006. Disponível em: 〈https://bit.ly/2VgCAeg〉. Acesso em: 18 dez. 2019.

TARDA, K. B.; RODRIGUES, R. V. A influência dos gastos em educação no crescimento econômico da região administrativa de campinas. Revista Estudo e Debate, v. 22, n. 2, dez. 2015. Disponível em: 〈https://bit.ly/2WQsxeZ〉. Acesso em: 13 mai. 2020.

TAVARES, M. C. Vida, ideias, teorias e política. São Paulo: Fundação Perseu Abramo, 2019.

TESOURO NACIONAL. Transferências Constitucionais. 2019. Disponível em: <http://sisweb.tesouro.gov.br/apex/ $\mathrm{f} ? \mathrm{p}=2600: 1>$. Acesso em: $11 \mathrm{dez} .2019$. THEIS, I. M.; GALVÃO, A. C. F. A formulação de políticas públicas e as concepções de espaço, território e região. Revista Brasileira de Estudos Urbanos e Regionais, v. 14, $\mathrm{n}^{\circ}$. 2 , p. 55-69, nov. 2012. Disponivel em: <https:/l bit.ly/2JOOUeI $>$. Acesso em: 18 dez. 2019. THOMAS, A. Development as practice in a liberal capitalistword, Journal of International Development, v. 12, p. 773787, 2000. Disponível em: <https://bit. ly/2Wwfkb5>. Acesso em: 06 de mai. de 2020.

TUDE, J. M.; FERRO, D.; SANTANA, F. P. Gestão de Políticas Públicas. Curitiba: IESDE BRASIL. 2015

VIS DATA - Visualizador de dados sociais. Assistência Social. 2019a. Disponível em: 〈https://bit.ly/38Do3uh〉. Acesso em: $16 \mathrm{dez}$. 2019.

VIS DATA - Visualizador de dados sociais. Dados Demográficos: População. 2019b. Disponível em: 〈https://bit.ly/35cFnHt〉. Acesso em: 11 dez. 2019.

WOOLDRIDGE, J. M. Introdução à econometria, $6^{\text {a }}$ ed. São Paulo: Cengage Learning, 2016. 